\section{OPEN ACCESS}

Edited by:

Anthony Grehan,

National University of Ireland Galway,

Ireland

Reviewed by:

Alan David Fox

University of Edinburgh,

United Kingdom

Mustafa Yucel,

Middle East Technical University,

Turkey

*Correspondence: Lauren S. Mullineaux

Imullineaux@whoi.edu

${ }^{\dagger}$ These authors have contributed equally to this work.

Specialty section: This article was submitted to Deep-Sea Environments and Ecology, a section of the journa

Frontiers in Marine Science

Received: 20 September 2017 Accepted: 02 February 2018 Published: 21 February 2018

Citation:

Mullineaux LS, Metaxas A Beaulieu SE, Bright M, Gollner S, Grupe BM, Herrera S, Kellner JB, Levin LA, Mitarai S, Neubert MG,

Thurnherr AM, Tunnicliffe $V$, Watanabe HK and Won Y-J (2018) Exploring the Ecology of Deep-Sea Hydrothermal Vents in a Metacommunity Framework. Front. Mar. Sci. 5:49. doi: 10.3389/fmars.2018.00049

\title{
Exploring the Ecology of Deep-Sea Hydrothermal Vents in a Metacommunity Framework
}

\author{
Lauren S. Mullineaux ${ }^{1 * t}$, Anna Metaxas ${ }^{2 \dagger}$, Stace E. Beaulieu ${ }^{1}$, Monika Bright ${ }^{3}$, \\ Sabine Gollner ${ }^{4}$, Benjamin M. Grupe ${ }^{5}$, Santiago Herrera ${ }^{6}$, Julie B. Kellner ${ }^{1}$, Lisa A. Levin ${ }^{7}$, \\ Satoshi Mitarai ${ }^{8}$, Michael G. Neubert ${ }^{1}$, Andreas M. Thurnherr ${ }^{9}$, Verena Tunnicliffe ${ }^{10}$, \\ Hiromi K. Watanabe ${ }^{11}$ and Yong-Jin Won ${ }^{12}$ \\ ${ }^{1}$ Biology Department, Woods Hole Oceanographic Institution, Woods Hole, MA, United States, ${ }^{2}$ Department of \\ Oceanography, Dalhousie University, Halifax, NS, Canada, ${ }^{3}$ Department of Limnology and Bio-Oceanography, University of \\ Vienna, Vienna, Austria, ${ }^{4}$ Department of Ocean Systems, NIOZ Royal Institute for Sea Research and Utrecht University, Den \\ Burg, Netherlands, ${ }^{5}$ Institute of Ocean Sciences, Fisheries and Oceans Canada, Sidney, BC, Canada, ${ }^{6}$ Department of \\ Biological Sciences, Lehigh University, Bethlehem, PA, United States, ${ }^{7}$ Integrative Oceanography Division, Center for Marine \\ Biodiversity and Conservation, Scripps Institution of Oceanography, La Jolla, CA, United States, ${ }^{8}$ Marine Biophysics Unit, \\ OIST, Okinawa, Japan, ${ }^{9}$ Lamont-Doherty Earth Observatory, Palisades, NY, United States, ${ }^{10}$ Department of Biology, School \\ of Earth and Ocean Sciences, University of Victoria, Victoria, BC, Canada, " ${ }^{11}$ Department of Marine Biodiversity, Japan \\ Agency for Marine-Earth Science and Technology, Yokosuka, Japan, ${ }^{12}$ Division of EcoScience, Ewha Womans University, \\ Seoul, South Korea
}

Species inhabiting deep-sea hydrothermal vents are strongly influenced by the geological setting, as it provides the chemical-rich fluids supporting the food web, creates the patchwork of seafloor habitat, and generates catastrophic disturbances that can eradicate entire communities. The patches of vent habitat host a network of communities (a metacommunity) connected by dispersal of planktonic larvae. The dynamics of the metacommunity are influenced not only by birth rates, death rates and interactions of populations at the local site, but also by regional influences on dispersal from different sites. The connections to other communities provide a mechanism for dynamics at a local site to affect features of the regional biota. In this paper, we explore the challenges and potential benefits of applying metacommunity theory to vent communities, with a particular focus on effects of disturbance. We synthesize field observations to inform models and identify data gaps that need to be addressed to answer key questions including: (1) what is the influence of the magnitude and rate of disturbance on ecological attributes, such as time to extinction or resilience in a metacommunity; (2) what interactions between local and regional processes control species diversity, and (3) which communities are "hot spots" of key ecological significance. We conclude by assessing our ability to evaluate resilience of vent metacommunities to human disturbance (e.g., deep-sea mining). Although the resilience of a few highly disturbed vent systems in the eastern Pacific has been quantified, these values cannot be generalized to remote locales in the western Pacific or mid Atlantic where disturbance rates are different and information on local controls is missing.

Keywords: metacommunity, metapopulation, hydrothermal vent, connectivity, resilience, disturbance, species diversity, dispersal 


\section{METACOMMUNITY FRAMEWORK AS A MULTISCALE APPROACH TO VENT DYNAMICS}

When the unique, lush animal communities at deep-sea hydrothermal vents were first discovered in 1977, scientists focused much of their inquiry on species traits, such as the unusual morphologies and adaptations, and on the large body sizes and population densities despite the paucity of input from surface primary production. Attention then broadened to the scale of vent habitats, including distribution patterns and interactions between species and their fluid environment. As more vents were discovered, research focus expanded to a regional and even global scale, exploring the processes that allowed ecological and genetic connectivity (exchange of individuals and genes) among some widely separated vents, while creating biogeographic boundaries among others. At roughly the same time that this expansion in scale of vent investigations was occurring, metapopulation theory was increasingly being applied to both terrestrial and aquatic ecosystems (Hanski and Simberloff, 1997; Sale et al., 2006). The metapopulation concept, and its multi-species, metacommunity analog, have opened a new way to frame ecological questions that involve both local and regional processes (e.g., Leibold et al., 2004; Logue et al., 2011). It is rapidly becoming a key tool for developing science-based societal solutions to managing fisheries (Guichard et al., 2004), protecting vulnerable ecosystems, and predicting how effects of point-source human disturbance (e.g., mining, pollution) propagate regionally. For hydrothermal vent systems, however, metapopulation and metacommunity theory remains largely unused (but see Jollivet et al., 1999; Neubert et al., 2006).

In this review, we explore the challenges and potential benefits of applying metacommunity theory to vent communities, and draw comparisons with cold seeps, both of which are systems with spatially fragmented distributions. The goal is to inform ecologists who work on deep-sea patchy ecosystems about the value of the metacommunity approach, and to inform metacommunity modelers about unique attributes of vent ecosystems. We present and synthesize field observations on aspects of vent communities relevant to metacommunity processes, identifying data gaps that need to be filled to answer key questions. Finally, we evaluate whether and how the metacommunity concept can be used to predict resilience in these systems, defined here as the ability to maintain or recover overall function and structure in the face of natural and human disturbance. We consider disturbance along a spectrum, ranging from catastrophic events that eradicate entire communities to more modest environmental changes that influence the ability of individual species to colonize and persist.

\section{Metacommunity Theory}

A population is a collection of individuals of a single species that are interacting with each other, reproducing, and dying. Classical theory for population dynamics is rooted in demographythe study of how the rates of development, survival, and reproduction depend upon environmental conditions (including population density) and how those rates give rise to patterns of change in population-level properties such as population growth rate, equilibrium population size and extinction probability.

A metapopulation is a population of populations. As originally conceived by Levins (1969), it is a collection of populations occupying distinct spatial locations, or "patches." These populations interact with each other as individuals disperse between them. Populations "reproduce" by colonizing unoccupied patches. Each population is also vulnerable to extinction, typically as the result of a disturbance to the patch. The balance between colonization of unoccupied patches and local extinctions determines the dynamics of the metapopulation and quantities such as the proportion of patches occupied at equilibrium.

Levins $(1969,1970)$ translated these ideas into a simple mathematical model called a patch-occupancy model because it tracks the occupancy state of patches of habitat. According to this model, some but not all patches are occupied at any one time (some can become colonized while others may go extinct). Occupied patches produce colonizers that can settle randomly on any patch, some of which are empty (see Box 1). The number of occupied patches changes over time at a rate that is the difference between the colonization and local extinction rates (Eq. 1). Patch-occupancy models make two important, but implicit, assumptions (Caswell and Cohen, 1993). The first is that within-patch dynamics, which are ignored, occur much more quickly than other processes in the metapopulation. The second is that the spatial arrangement of patches is not important. Patches can be colonized by individuals originating in any other patch; the only spatial scales that appear are the local patch scale and the metapopulation scale.

Other mathematical formulations of metapopulation dynamics-including coupled map lattices (Kaneko, 1993), which track within-patch population density, and cellular automata (Caswell and Etter, 1993; Molofsky, 1994; Keymer et al., 1998), which account for the spatial arrangement of habitat-relax some of these assumptions. In doing so, these models generate a richer set of dynamical behaviors than patch occupancy models, and allow the modeler to address a much larger set of interesting ecological questions. There is, however, a trade off: coupled map lattices and cellular automata are typically less mathematically and computationally tractable than patch occupancy models.

Despite its obvious simplicity, the metapopulation concept represents an important advance in theoretical ecology (Hanski and Gilpin, 1991). By shifting focus away from the interactions among individuals within a population toward the interactions between populations, and through the formulation of simple mathematical descriptions of metapopulation dynamics, Levins and others, who have extended his ideas since, have provided a powerful way to address a suite of ecological questions that continue to be pursued by both theoretical and empirical ecologists. Of particular interest has been the way in which the spatial distribution of viable habitat, the production of offspring, the dispersal behavior of individuals (which together influence colonization rates), and disturbance (which influences local extinction rates) 
BOX 1 | Mathematical formulation of the patch-occupancy model proposed by Levins.

Levins $(1969,1970)$ imagined a large number of habitat patches, $N$, of which $X(t)$ are occupied at time $t$. The remainder, $N-X(t)$, are empty and available for colonization by individuals dispersing from the occupied patches. Imagine that each occupied patch produces potential colonizers at the rate $c$. These propagules settle, randomly, on any patch; a fraction $(N-X) / N$ land on empty patches that they colonize. The total colonization rate is then $c X(N-X) / N$. Occupied patches are assumed to suffer extinction events at the rate $e$. The number of occupied patches changes over time at a rate that is the difference between the colonization and local extinction rates; i.e.,

$$
\frac{d X}{d t}=c X \frac{(N-X)}{N}-e X
$$

The rate of change of the proportion of all patches that are occupied, $x=X / N$, measured in time units chosen so that the average persistence time of a local population is 1 (i.e., $\tau=$ et), is even simpler:

$$
\frac{d x}{d \tau}=r x(1-x)-x
$$

where $r=c / e$.

After a sufficient period of time, the proportion of occupied patches in the metapopulation comes to an equilibrium at the level $x^{*}=(r-1) / r$ as long as $r>1$ and $x(0)>0$. If $r<1$, global extinction is assured in the long run.

Note that under model (1), while aggregate descriptions of the entire metapopulation (like the proportion of occupied patches, $x$ ) come to equilibrium, no individual patch is at equilibrium. Individual patches continue to change state between unoccupied and occupied.

interact to determine whether species persist, and for how long.

A metacommunity (Gilpin and Hanski, 1991; Wilson, 1992) has similar spatial structure as a metapopulation but includes multiple species that may interact with each other through trophic interactions, facilitation, competition, or other processes. These interactions can influence colonization by modifying the rates of production of dispersers, and by determining which of those dispersing individuals are able to invade a given local community. For example, a specialist predator may only be able to colonize a patch that is already occupied by its prey, or an individual may not be able to colonize a patch already occupied by a population of a superior competitor. Interactions can also affect local extinction if colonizers displace resident species.

An important aspect of any metacommunity dynamic model is the specification of the interspecific interactions. The number of potential pairwise interspecific interactions between $s$ species can be as large as $s(s-1) / 2$. The number of possible patch states grows even more quickly with the number of species. To simplify, theoreticians often limit the number of species in their model metacommunities and limit the number of interactions between species by making strong biological assumptions. For example, to capture successional dynamics (the change in species structure over time), Neubert et al. (2006) specified a strict hierarchy wherein species with higher ranks could only colonize patches that were previously colonized by species lower in the hierarchy. Alternatives to the facilitation model of succession are the tolerance model (wherein any species can colonize available habitat first) or the inhibition model (wherein early colonizers modify the environment to preclude later colonizers; Connell and Slatyer, 1977).

A key feature of both metapopulation and metacommunity theory is the ability to incorporate multiple scales, while recognizing that different processes may apply at the different scales. When a local community is embedded in a metacommunity, its dynamics are influenced not only by birth rates, death rates and interactions of populations spawned at the local site, but also by dispersal. The connections to other communities provide a mechanism for dynamics at a local site to affect features of the regional biota. Metacommunity models tend to approach ecological questions from different perspectives (Leibold et al., 2004), each of which emphasizes a different dominant influence, including patch quality ("species sorting"), dispersal ("patch dynamics"), or the influence of immigration on local competitive exclusion ("mass effects"). At deep-sea hydrothermal vents, the dominant influence is likely to vary, depending on the geological and oceanographic setting.

\section{Integrating Metacommunity Theory and Field Observations}

Interpreting field observations from a metacommunity perspective can be a challenge, as most field studies focus on either local (e.g., species' responses to local environment or species interactions) or regional (e.g., dispersal, colonization) processes, but not both. However, to fully understand the processes driving community structure, species diversity and resilience, observations are needed at both scales. Studies from a few terrestrial habitats stand out as examples of this combined approach. In a system of pitcher plants inhabited by a community of protists and their mosquito-larvae predators, a manipulative field study showed that dispersal frequency increased the number of species in individual plants, but only in the absence of predators (Kneitel and Miller, 2003). Similarly, in a system of ponds, dispersal between sites increased diversity of resident zooplankton communities, despite the strong site-specific influences of macrophyte cover and fish predation (Cottenie et al., 2003). In contrast, in a pond system where individual ponds differed in permanence (some dried up), disturbance rate, rather than dispersal distance, was the primary influence on community structure (Urban, 2004). In systems 
such as rivers where dispersal is strongly directional, the spatial arrangement of sites may become important. For example, an investigation of benthic invertebrates in a dendritic (branching) river showed that the community was influenced mainly by local environmental conditions in the isolated headwaters, but by dispersal in the mainstream sections (Brown and Swan, 2010).

Field studies of marine metacommunities are uncommon, but one study of coral reef fish species showed that species composition in individual reef sites was influenced mostly by local habitat structure for many functional groups (e.g., planktivores, corallivores and piscivores), while dispersal appeared to be important for others (detritivores and grazers) (MacNeil et al., 2009). In both marine and terrestrial systems, it is becoming clear that understanding resilience to disturbance requires investigation of dispersal in addition to local influences, as demonstrated by field studies in estuaries (Thrush et al., 2008), forests (Bloch et al., 2007), and streams (Campbell et al., 2015).

\section{Vent Communities as Metacommunities}

To understand why deep-sea hydrothermal vents are particularly well suited to application of metacommunity theory, we provide some background on their environmental setting and biological communities. Hydrothermal vents form in geologically and tectonically active areas of the seafloor where heated, chemicalrich fluids escape up through cracks in the ocean crust (explained further in section Global Patterns of Vent Distributions, Disturbance Frequency, and Longevity). Where these fluids mix with oxygenated seawater, they support lush communities fueled by microbial chemoautotrophy. The large size, high densities and taxonomic novelty of organisms discovered at hydrothermal vents challenged the prevailing view of the deep sea as a sparsely populated desert inhabited mostly by small individuals.

Vent communities occur in all ocean basins, with over 500 deep-sea vent fields having been observed along mid-ocean spreading centers and in subduction zones (Figure 2; Beaulieu et al., 2015). Vents occur in discrete patches (vent fields) that may be separated by a few to many hundreds of $\mathrm{km}$ and may comprise multiple vent orifices. The intervening areas of seafloor lack the hydrothermal fluids, and associated microbes, that fuel vent food webs. As a result, most species inhabiting deep-sea vents, including over 500 species of invertebrates (Desbruyères et al., 2006), cannot persist in typical marine habitats, and are endemic to vents.

Many deep-sea vent communities are transient because they are perched on top of active volcanoes and other dynamic seafloor features. The distances between vent patches and the disturbance rate at vents depend on the magmatic, tectonic and hydrological processes that result in release of hydrothermal fluids (Fornari and Embley, 1995; detail in section Global Patterns of Vent Distributions, Disturbance Frequency, and Longevity). In areas with relatively high magma supply, such as the eastern Pacific, vents are spaced relatively closely but the communities may be eradicated by seafloor eruptions on decadal time scales. These natural eruptive disturbances may be a fundamental regulating feature of vent ecosystems at volcanically active areas. However, in areas with slower spreading rates, such as the mid-Atlantic Ridge and many backarc spreading systems, vents are spaced farther apart, but are subject to large eruptions less often. Here, age and stability are reflected in the large mineral deposits that have accumulated over many thousands of years (Jamieson et al., 2013). For many vent sites, our observation timeline (only decades) is too short to assess disturbance frequency.

Vent species are distributed in discrete biogeographic provinces, each of which has a characteristic fauna (e.g., Moalic et al., 2012), and extends through all or part of an ocean basin. Patterns of species diversity and occurrence differ between these regions. Diversity at an individual vent tends to be high in the eastern tropical Pacific, reduced in the northeastern Pacific, and low in the Atlantic (Juniper and Tunnicliffe, 1997; Tsurumi, 2003; Bachraty et al., 2009). Within a region, individual vent patches rarely host the full species pool (Van Dover et al., 2002). In some regions, neighboring vents may differ strikingly in species composition, as has been observed in the mid-Atlantic (Desbruyères et al., 2001) western Pacific (Podowski et al., 2010; Metaxas, 2011), and Gulf of California (Goffredi et al., 2017). In contrast, in the eastern Pacific, individual vents tend to host a subset of the province's species pool, without geographic clines (Juniper et al., 1990; Van Dover and Hessler, 1990).

These differences in patterns of species diversity and occurrence between ocean regions and between vents within regions have been attributed to various processes, including habitat variation (e.g., differences in the composition of the vent fluids between neighboring vent patches; Desbruyères et al., 2001), but disturbance frequency and dispersal barriers also likely play a role (O’Mullan et al., 2001; Mullineaux, 2014). Juniper and Tunnicliffe (1997) suggested that the rate of disturbance and habitat heterogeneity contribute to these patterns on ecological time scales, while regional (tectonic) age operates on differences on evolutionary scales. A high disturbance rate may result in low diversity at individual vents, but it may also result in a mosaic of communities at different stages in succession, thus elevating regional diversity. Alternatively, the spacing of vents, as well as the presence of transform faults and seamounts, can limit dispersal and the potential for recovery from perturbations and may even contribute to extinction of populations at individual vent fields (Turnipseed et al., 2003; Breusing et al., 2016).

The patchy distribution and species endemicity of vents underscore the importance of dispersal in maintaining population connectivity among vents. Since the adults of most species are sessile or of low motility, dispersal occurs mainly through planktonic larvae which, despite showing some behaviors, are mainly transported by currents (Adams et al., 2011, 2012). Larval retention within a vent field (scale of $\sim 100 \mathrm{~m}$ ) can be high and contributes to local larval supply (Metaxas, 2004). However, following catastrophic eruptions that extirpate local populations, larvae of some species from remote vents can quickly recolonize (Mullineaux et al., 2010).

Species interactions can dictate the sequence of successional patterns at hydrothermal vents. Competitive inhibition, facilitation, and habitat provision or modification influence the abundance of different species during initial colonization but also throughout the development of communities following a disturbance (Sarrazin et al., 1997; Mullineaux et al., 2003; 
Podowski et al., 2010). For instance, on the East Pacific Rise (EPR), the presence of the small tubeworm Tevnia may facilitate colonization by the giant tubeworm Riftia (Mullineaux et al., 2000) which then appears to be excluded by mussels. Predation can modulate local abundance of vent communities at any point in time, from colonization to community maturity, as described for fish predation on a dominant gastropod species (Micheli et al., 2002; Sancho et al., 2005).

The metacommunity concept appears to be particularly suitable as a framework for exploring the processes responsible for observed patterns in vent community composition, dynamics and persistence. The patchy distribution and transient nature of suitable habitat, along with the occurrence of chronic or episodic disturbance at various frequencies and magnitudes, underlie the importance of ecological connectivity (via larval dispersal) and succession in regulating community dynamics at hydrothermal vents. The interaction between dispersal ability and habitat distribution will determine recolonization potential, with particular sequences of succession dependent on subsequent facilitative or competitive interactions. Given the habitat topology, species distributions and endemicity, and species tolerance to a certain suite of environmental conditions, the models of patch dynamics and species sorting (Leibold et al., 2004) can be applied to communities at hydrothermal vents. Ecosystems at other deep-sea chemosynthetic habitats, such as cold seeps, and whale and wood falls, share some of the metacommunity attributes with hydrothermal vent ecosystems. Although the focus herein is on vents, seeps offer an interesting comparison, as they differ in the frequency and magnitude of disturbance, and their species overlap with the surrounding nonchemosynthetic deep-sea (Levin et al., 2016a).

\section{Objectives for Metacommunity Investigation}

Field studies of metacommunity dynamics are challenging in almost any habitat and are particularly difficult in the remote and difficult to access ecosystems of the deep sea. For that reason, the most promising approach in applying metacommunity theory to questions in vent ecology is in coupling metacommunity models with carefully targeted field observations. The models can be used to synthesize observations at local and regional scales, to explore hypotheses about what processes underlie observed patterns, and to direct future field efforts. They can also be used to explore community resilience and potential for recovery from natural and anthropogenic disturbances.

In this paper, we focus on three components of metacommunity dynamics that are relevant to vent systems: disturbance, regional controls, and local controls (Figure 1). Vent communities are particularly fascinating in the context of these components because of the global geological dynamics that control vent distributions and disturbance rates, the interactions between physical ocean dynamics and seafloor topography that mediate ecological connectivity, and the unusual suite of species that participate in chemosynthesis-based food webs. The differences across and between ocean basins in disturbance rates, current-mediated dispersal, and species composition provide a natural laboratory for comparative studies of metacommunity processes, and their influence on diversity, persistence, and resilience of these unique communities. Field observations from various vent systems (and related chemosynthetic habitats) that can inform this effort are presented in section Field Observations and Synthesis, and a set of key questions that are feasible to address are proposed in section Synthesis of Field Observations and Key Questions. In section Evaluating Resilience to Human Disturbance, we apply observations and theory to the topic of vulnerability and resilience to disturbance of vent communities, and the extent to which vulnerability and resilience can be predicted and evaluated for management decisions on seafloor mining and protected areas.

\section{FIELD OBSERVATIONS AND SYNTHESIS}

\section{Global Patterns of Vent Distributions, Disturbance Frequency and Longevity}

The global distribution of hydrothermal vents aligns with sources of heat deep in Earth's lithosphere-in general, magma upwelling at plate boundaries (Figure 2; Beaulieu et al., 2013, 2015). Buoyant fluids from sub-seafloor hydrothermal circulation are expressed as focused or diffuse vents, often found in close proximity (on the order of $10-100 \mathrm{~m}$ ) and forming vent fields. The spatial scale of a vent field best matches the spatial scale of a "patch" for metacommunity dynamics. Delineation of vent fields can be challenging and often is based on separation distance, e.g., $>1 \mathrm{~km}$ (Beaulieu et al., 2013). As of 2015, the global inventory of vent fields was 572 at depths $>200 \mathrm{~m}$, with 344 at mid-ocean ridges, 117 at back-arc spreading centers, 106 at volcanic arcs, and 5 at intraplate hotspots (Beaulieu, 2015).

On spreading ridges, the range in expected spacing between vent fields is from 25 to $90 \mathrm{~km}$, inversely proportional to the magnitude of the spreading rate $(150-10 \mathrm{~mm} / \mathrm{yr}$; Beaulieu et al., 2015); however these distances may be over-estimates. For example, although previous observations indicated a spacing of $\sim 20-25 \mathrm{~km}$ between vent fields from 9 to $13^{\circ} \mathrm{N}$ on the fastspreading East Pacific Rise (EPR; Beaulieu, 2015), a spacing of $3 \mathrm{~km}$ may be more accurate (Baker et al., 2016). Also, venting has been observed off-axis at ridge flanks but has not been studied well (Haymon et al., 2005). At volcanic arcs, average spacing between volcanic centers can be as little as $20-30 \mathrm{~km}$, but not all of these are volcanically or hydrothermally active (de Ronde et al., 2007; Baker et al., 2008). Hydrothermal vents are found at a wide range of depths from $<200$ to $\sim 5,000 \mathrm{~m}$; some vent fields that appear closely spaced horizontally may differ greatly in depth (e.g., the Von Damm and Piccard vent fields in the Caribbean Sea are only $\sim 20 \mathrm{~km}$ apart in latitude/longitude but differ by $\sim 2,600 \mathrm{~m}$ in depth). Furthermore, the spatial variation of patch quality, as influenced by vent fluid composition, differs between ridges. Although some ridges may have similar composition of venting fluids across great distances (e.g., 1,000-km scale on the basalt-hosted EPR), others have diverse chemistries [e.g., 100-km scale due to the combination of basalt- and ultramafic-hosted systems on the Mid-Atlantic Ridge (MAR); Schrenk et al., 2013; German et al., 2016]. Arc/back-arc settings may have vent fields 


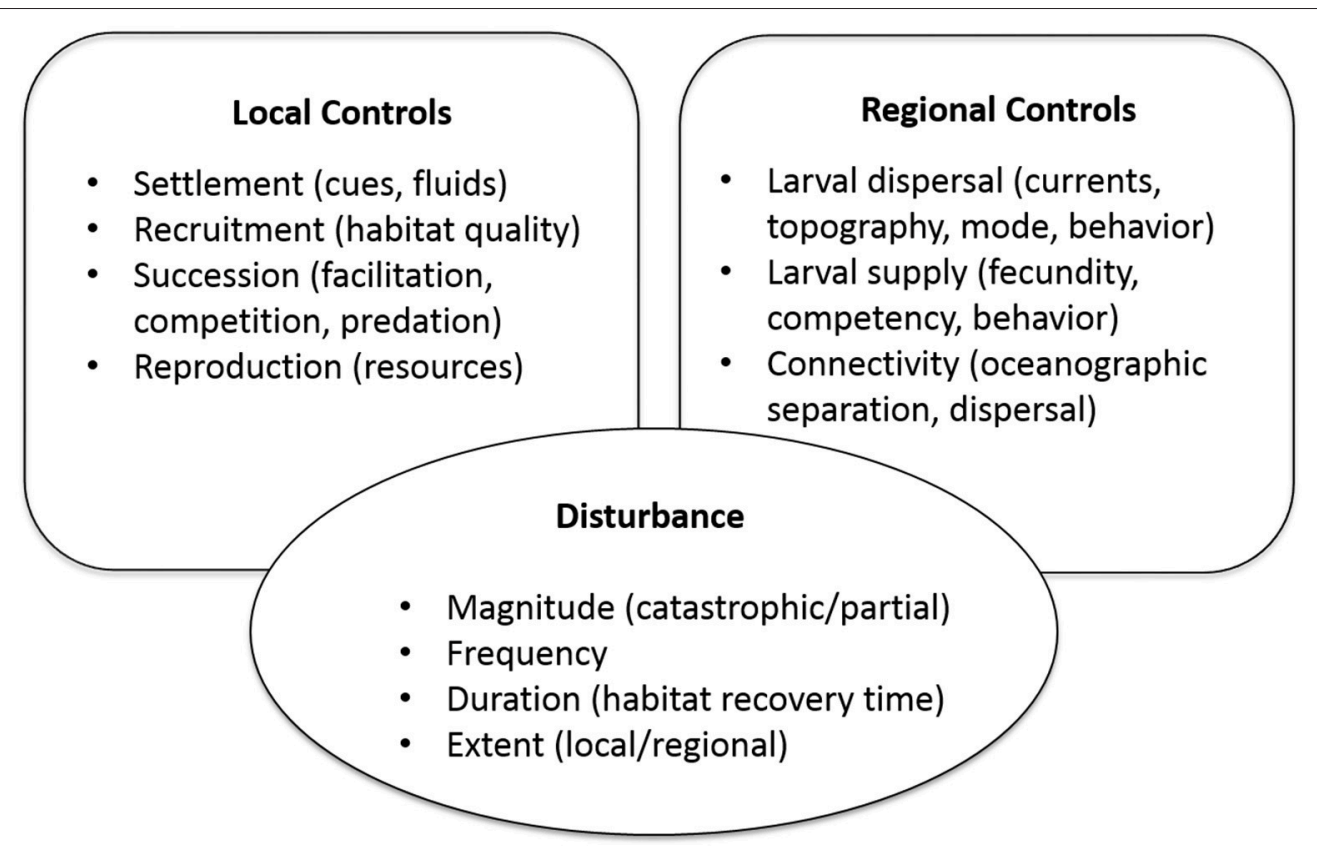

FIGURE 1 | Processes affecting metacommunity dynamics through local controls (influences of habitat and biological interactions), regional controls (larval exchange, connectivity, and gene flow), and disturbance. Examples in parentheses are of specific features, influences, or characteristics.

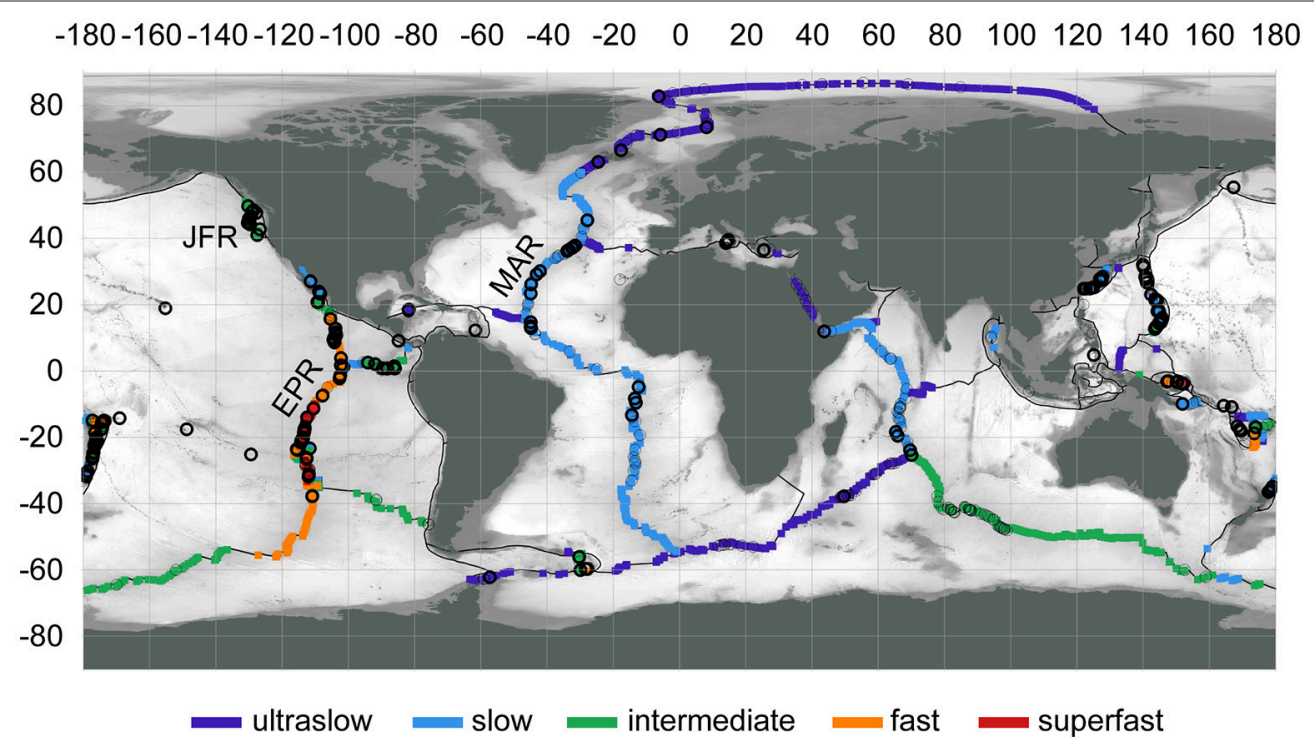

FIGURE 2 | Locations of active hydrothermal vent fields (circles), confirmed (thick outline) or inferred (thin outline), at water depths $>200 \mathrm{~m}$. Spreading rates categorized to: ultraslow (<20 mm/yr), slow (20-50 mm/yr), intermediate ( $50-80 \mathrm{~mm} / \mathrm{yr})$, fast (80-140 mm/yr), superfast (>140 mm/yr). Region labels: EPR, East Pacific Rise; JFR, Juan de Fuca Ridge; MAR, Mid-Atlantic Ridge. Map data: InterRidge Vents Database Version 3.3 (Beaulieu, 2015), PB2002 plate boundaries (Bird, 2003), ETOPO1 bathymetry (Amante and Eakins, 2009). Map produced with QGIS 2.18 (QGIS DevelopmentTeam, 2017).

that greatly differ in fluid chemistry at the $10-\mathrm{km}$ scale (German and Seyfried, 2013).

Natural disturbance at vents occurs mainly at the local scale through volcanic eruptions or landslides but may also result from tectonic events such as earthquakes, that affect the regional scale (Van Dover, 2014). For the patch occupancy model of metapopulation dynamics, major disturbance that eradicates the community for an entire patch may occur abruptly (over the course of days) - for example, through emplacement of lava after a volcanic eruption or through mass wasting from a landslideor may take some time (years), as in the cessation of venting. Disturbance may also create new habitat. The frequency of 
disturbance may range from almost continuous at vents on submarine arc volcanoes with multiyear eruptions (e.g., NW Rota-1; Rubin et al., 2012; Schnur et al., 2017) to very infrequent at vents hosted in ultraslow spreading settings. At spreading ridges, the frequency of volcanic eruptions is related to timeaveraged magma supply and spreading rate (Perfit and Chadwick, 1998). For example, at the fast-spreading EPR, vent communities have been observed to be eradicated by seafloor eruptions on decadal time scales (Rubin et al., 2012), but at the slow-spreading MAR an eruption might not occur for 10,000 years (Perfit and Chadwick, 1998). Some arc volcanoes "grow and collapse on human timescales" due to frequent eruptions as well as landslides (Schnur et al., 2017). Other non-volcanic natural disturbances, such as earthquake activity or cessation of a vent within the patch, may lead to minor to moderate disturbances that affect patch size or quality. In general, at fast-spreading ridges, earthquakes tend to be frequent but too small in magnitude to impact vent fauna (e.g., $\sim 10$ per day at magnitude $<2$ on the EPR; Tolstoy et al., 2006). At slow-spreading ridges earthquakes of greater magnitude tend to be more common (Dziak et al., 2012). For example, on the MAR the frequency of events with magnitude $>3$ was $\sim 1$ per $\mathrm{km}$ of ridge axis per year, with larger events (magnitude $>5$ ) $\sim 1$ per $\mathrm{km}$ of ridge axis per 100 years (Escartín et al., 2008).

The longevity of hydrothermal systems depends on the setting. For example, long-lived vent fields have deep and stable conduits for hydrothermal circulation, whereas venting in the aftermath of volcanic eruptions may be short-lived. In general, at spreading ridges the shortest-lived vent fields occur at fastspreading ridges, where they are under magmatic control, and the longest-lived (i.e., "thousands of years"; German et al., 2016) at slow-spreading systems controlled by tectonics. The age of a vent (time since initiation of hydrothermal activity) differs from longevity (duration of most recent hydrothermal activity), since hydrothermal activity may wax and wane over time (Cherkashov et al., 2017). Age tends to be inversely related to spreading rate (Jamieson et al., 2013), ranging from $\sim 100$ years at $13^{\circ}$ $\mathrm{N}$ vent field on the fast-spreading EPR (Lalou et al., 1985) to $\sim 20,000$ years at the TAG active field on the slow-spreading MAR (Cherkashov et al., 2017), but less is known about longevity. Hydrothermal systems at volcanic arcs may be active for several thousands of years (e.g., Kermadec arc; de Ronde et al., 2007), whereas others may have decadal spans of activity that are more intimately related to volcanic cycles (Embley et al., 2014).

\section{Local Controls of Environment and Species Interactions}

Local environmental conditions in vent habitats can be extreme and variable, and exert a strong influence on species occurrence. Undiluted hydrothermal fluids exit the seafloor at temperatures that may exceed $400^{\circ} \mathrm{C}$, and often are characterized by low oxygen levels, low $\mathrm{pH}$, and elevated concentrations of toxic metals. Only where the fluids mix with ambient seawater are the conditions suitable for vent communities. At this interface, microbial chemosynthetic production, fueled by reducing compounds such as hydrogen sulfide or methane, provides the trophic base for vent ecosystems. Thus, the location and flux of hydrothermal fluids constrain organismal distributions, depending on the species' physiological tolerances and their nutritional requirements. Measurements at vents with precisely placed probes have demonstrated a close correspondence between distributions of individual species and temperature, $\mathrm{pH}$, oxygen, hydrogen sulfide, and various metal compounds (Sarrazin et al., 1999; Luther et al., 2001; Matabos et al., 2008a).

Differences in the chemical composition of vent fluids between vent fields have the potential to affect species occurrence, as do other characteristics, such as substratum type and depth. In the Lau Basin (western Pacific), along a 400-km long segment of the spreading center, a latitudinal gradient in lava type (basaltic to andesitic) and associated hydrothermal fluid chemistry is correlated with species composition in vent communities (Podowski et al., 2010). At some unusual vent sites in this region, where smoker chimneys are distinctly reddish brown, snails and mussels are notably absent, replaced by low densities of shrimps, crabs, polynoid polychaetes, and limpets. This faunal anomaly may be in response to high metal concentrations (Mottl et al., 2011). On the northern MAR, vent communities along a $3,000 \mathrm{~km}$ section between 11 and $38^{\circ} \mathrm{N}$ differ markedly in species composition, in patterns that correspond to both depth and fluid chemistry (Desbruyères et al., 2000).

Species composition may vary between vent sites that share a similar geological setting but differ in the extent of subseafloor mixing of vent fluids with seawater. The plumbing system that delivers vent fluids up to the seafloor typically creates distinct spatial gradients in the flux and concentration of vent fluids that correspond to species distributions. If the high-flux end of this gradient (where there would be more reduced compounds and thus greater productivity) is missing at a particular vent, the species that rely on those environmental conditions also will be absent. On the EPR, communities display a striking zonation in the large foundation species: Pompeii worms live directly on the black smoker chimneys, while giant tubeworms (siboglinid polychaetes, formerly known as vestimentiferans) occur in vigorous "diffuse" (diluted) fluid flux, mussels and clams in moderate flux, and various suspension feeders, including barnacles and serpulid polychaetes, in weak flux (Hessler et al., 1985; Micheli et al., 2002). Smaller species (macro- and meiofauna) also exhibit zonation (Mills et al., 2007; Gollner et al., 2010). Analogous patterns are seen on the Juan de Fuca Ridge, where a species of alvinellid worm dominates the high-flux habitats, while a mixed assemblage of a siboglinid tubeworm, polychaetes, and gastropods inhabit lowerflux environments (Sarrazin et al., 1999). In the Lau Basin, one large species of snail is found in the high flux areas, a second snail species in moderate flux, and mussels in lower flux (Podowski et al., 2010). On the MAR, the high-flux regions are populated by shrimp, followed along the flux gradient by mussels, and grazers and suspension feeders (Cuvelier et al., 2009). In vent fields on the East Scotia Rise (Southern Ocean), assemblages in high flux are dominated by yeti crabs, whereas lower fluxes are inhabited by small gastropods, stalked barnacles, and carnivorous anemones (Marsh et al., 2012). 
Field observations of species interactions at vents are difficult to obtain, but information about trophic interactions, competition and facilitation is available for several regions. Most vent species can be classified into major trophic groups of producers (in association with bacterial symbionts), grazers and suspension feeders, predators and scavengers, and parasites, based on morphological and stable isotopic analyses (e.g., Fisher et al., 1994; Colaço et al., 2002; Reid et al., 2013). In some cases, a species may function at multiple trophic levels. For example, mussels may host symbionts and suspension feed, gastropods have symbionts and also graze, and crabs often are opportunistic predators and scavengers. Behavioral observations, exclusion experiments, and gut-content analyses provide more detail on interactions, such as demonstrating that specialized feeding of a vent fish on a dominant limpet in vents on the EPR allows a diverse group of gastropod grazers to persist (Micheli et al., 2002; Sancho et al., 2005). While competitive interactions between grazers (e.g., active displacement of new recruits) have been observed or inferred in areas with high fluid flux at vents in the eastern Pacific (Mullineaux et al., 2003; Bates et al., 2005), facilitative interactions also occur. In most cases, the facilitation is by sessile, tube-dwelling species that appear to disrupt grazers of, or provide habitat for, new colonizers (Mullineaux et al., 2003; Govenar, 2010), but gregarious settlement of gastropods and tubeworms has also been proposed (Kelly et al., 2007; Short and Metaxas, 2011). Aggregations of large, symbiont-hosting species, such as giant tubeworms and mussels, have the potential to strip hydrogen sulfide from vent fluids (e.g., Johnson et al., 1988), making a patch inhospitable to new colonists. The sorts of interactions described here may be important in primary succession and are discussed further in section Regional and Local Influences on Succession.

\section{Range of Capabilities for Planktonic Dispersal}

Benthic invertebrates with low to no motility as adults, such as the species that dominate hydrothermal vents, exhibit a suite of different reproductive and life history strategies, which in turn affect dispersal potential and colonization ability. For example, some species may reproduce continuously, producing small numbers of larvae at any one time throughout the year. Others can reproduce over a short period of time, when the entire population is synchronized, and all larvae are released at the same time. In the former scenario, recruitment may be continuous, and in the latter discontinuous, showing episodic peaks over time. Although much still remains unknown, the species that inhabit vents exhibit the entire range of reproductive and life history strategies known for benthic invertebrates. For example, some species show synchronous reproduction with discontinuous recruitment while others show asynchronous reproduction and continuous recruitment. The latter strategy may be more relevant for ensuring rapid local colonization after a continuous disturbance or for long-distance dispersal after a catastrophic disturbance as some proportion of the population is always in a reproductive state and can provide larvae. Reproductive output can be influenced by patch quality, being greatest in areas of vigorous fluid flux and lowest in senescing vents (Kelly and Metaxas, 2007).

Dispersal potential is influenced by a number of biotic factors (including larval feeding mode, duration of the larval period, larval physiology and behavior) and abiotic factors (e.g., ocean circulation, hydrothermal plume characteristics, density structure of the water column; see section Physical Transport and Ecological Connectivity). The biotic factor most widely believed to influence dispersal potential in vent species is planktonic larval duration (Hilario et al., 2015). Larvae may be planktotrophic, feeding in the water column, and thus able to survive for long periods before needing to find a suitable location to settle. Or they can be lecithotrophic, relying on energy stores in the egg and thus limited in the time they can spend in the plankton before starving. Larval duration has been calculated from larval culturing studies for only a few vent species at hydrothermal vents and it ranges from roughly 6 weeks for siboglinid tubeworms (38 days for Riftia pachyptila in (Marsh et al., 2001); 45 days for Lamellibrachia satsuma in Miyake et al., 2006) to more than 3 months for a crustacean (the barnacle Neoverruca intermedia, Watanabe et al., 2004). Indirect methods have been used to infer larval durations of many months for bresiliid shrimp (Herring and Dixon, 1998). In general, a longer duration implies a greater dispersal potential. However, this does not necessarily confer higher recruitment success for species at hydrothermal vents, particularly at mid-ocean ridges and seamounts, where a longer larval duration may result in loss from a region of suitable habitat (e.g., Marsh et al., 2001).

Larval duration is in turn influenced by a number of intrinsic characteristics, such as larval feeding mode and physiological tolerances. A wide variety of larval developmental modes occurs at vents, ranging from direct development, which is associated with extremely low dispersal potential mostly in direct proximity to the adults, to indirect development of either planktotrophic or lecithotrophic larvae. Many vent invertebrate species considered to date have lecithotrophic larvae, relying entirely on energy stores provided in the egg, thus with a predetermined larval period (Van Dover, 2000), others are lecithotrophic for at least part of their development (Marsh et al., 2001), but may feed in later stages. Energy availability is, in turn, determined by respiration rates, which can vary greatly with temperature. Larval duration for lecithotrophs can be prolonged, and thus dispersal potential enhanced, if development can proceed in the low temperature of ambient seawater as larvae disperse between vents (see Pradillon et al., 2005). Species such as mussels and crabs exhibit planktotrophic larval development, which is not limited by energy stores but can continue as long as the larvae can locate and consume food (e.g., Herring and Dixon, 1998; Trask and Van Dover, 1999). It is suggested that these larvae have great dispersal potential and can migrate in the water column hundreds of meters above the vents. The availability of food in the water column, as well as exposure to a wide range of temperatures, will directly affect development rate for these larvae. Consequently, physiological tolerance to temperatures on-vent (high) and off-vent (low) can influence larval duration and dispersal potential irrespective of larval developmental mode. 
Larval behavior has been shown to influence larval dispersal potential in shallow water systems (Daigle et al., 2016) but has been less studied at hydrothermal vents. Here, we define larval behavior as a modification in the larva's horizontal or vertical position by active swimming. Larval swimming speeds are weak relative to horizontal current velocities, but less so relative to time-averaged vertical velocities. In shallow water systems, larval swimming has been reported to modify larval vertical position and expose them to different current velocities and density layers. At hydrothermal vents, fluid motions are influenced by local processes, as well as regional circulation. For instance, the hot vent fluids generate buoyant plumes that entrain ambient seawater and planktonic organisms and move them upward. On ridges, topographic interactions may cause current velocities near the seafloor to be stronger than a $100 \mathrm{~m}$ above. Consequently, in this setting, the role of larval swimming in larval transport is not clear. Observational studies have suggested that larval swimming toward the seafloor or induced passive sinking can be retentive, limiting dispersal distance, whereas modeling studies suggested that being near the seafloor rather than higher in the plume may actually increase dispersal, except when constrained by valley walls (McGillicuddy et al., 2010; Metaxas, 2011; Mullineaux et al., 2013). Although there is some evidence to support the role of behavior in larval retention at vents, more research is necessary on this topic.

From a metacommunity perspective, the wide range in reproductive strategies (including fecundity, spawning frequency and development) among species found at vents will influence the resilience to, and possible outcomes after, a disturbance. The combination of life-history variation (e.g., larval survival and settlement) and the frequency and magnitude of disturbance has been shown to affect local population resilience for at least one vent species, but likely many more, particularly in locations with highly retentive circulation (Kelly and Metaxas, 2010). The range in dispersal potential will determine the larval source to any vent field because of the spatial separation among vents. Consequently, the ranges in dispersal potential and colonization ability of different species will indirectly influence the outcome of species interactions within a vent field. Further, after a catastrophic disturbance, only those species with long-range dispersal potential will be available to colonize vents from a non-local larval source.

\section{Physical Transport and Ecological Connectivity}

Nearly all known hydrothermal vents are found on active spreading centers, or on the summit or flanks of arc- or intraplate volcanoes. In terms of dispersal, these sites can be grouped into three broad categories of larval sources: (i) topographic peaks of spreading centers (mostly fast-spreading ridges without deep median valleys and back-arc basins), (ii) inside median valleys of slower-spreading mid-ocean ridges, and (iii) seamounts. Of these settings, dispersal from sources in median valleys is most clearly constrained by topography. The depth of the rift valley covaries with ridge spreading rate. On ridges with slow spreading rates, such as the Mid-Atlantic Ridge, hydrothermal vent fields are often located so deep inside the rift valleys that not even the neutrally buoyant hydrothermal plumes rise above the valley walls (German et al., 1995), in which case near-field horizontal dispersal of passive particles is restricted to the along-valley direction. Velocity and hydrographic observations over several decades inside the MAR rift valley between $36^{\circ}$ and $38^{\circ} \mathrm{N}$, which contains at least 7 hydrothermal vent fields, are consistent with deep northward along-valley mean flow (Thurnherr et al., 2002, 2008). Evidence for southward return flow above the deep northward-flowing layer suggests that bi-directional dispersal along the valley is possible, at least for larvae capable of active vertical displacement. Similar unidirectional deep along-valley flows have been suggested from other rift-valley segments as well (Saunders and Francis, 1985; Wilson et al., 1995). For MAR, there is also evidence for persistent inflows of dense water across deep sills on the rift valley walls near 36 and $38^{\circ} \mathrm{N}$ (Thurnherr et al., 2002, 2008), implying mean upwelling within and out of the valley (exit pathway for rift-valley water).

Hydrothermal sources on fast-spreading mid-ocean ridges without median valleys tend to occur along the ridge crests, where topographic blocking does not constrain effluent and larval dispersal. At $9^{\circ} 50^{\prime} \mathrm{N}$ on the East Pacific Rise (EPR), long-term dispersal (years to decades) of the hydrothermal effluents is primarily westward across the Pacific (Lupton, 1998; Thurnherr et al., 2011), although short-term dispersal may not be limited to the west. This pattern is common in the deep ocean where horizontal dispersal on time scales of weeks to months is often omnidirectional (dominated by eddy stirring) and unidirectional advection by the weak mean flows only becomes dominant on longer time scales (Speer et al., 2003). Even though the ridge topography along the EPR near $9^{\circ} 50^{\prime} \mathrm{N}$ does not extend significantly above the hydrothermal sources, strong, narrow boundary currents along the upper ridge flanks can cause dispersal on time scales of weeks to favor the alongridge directions (McGillicuddy et al., 2010). Because of horizontal and vertical shear associated with these ridge-crest boundary currents, dispersal depends on larval vertical positioning and the direction of the instantaneous flow at the time of larval release (Jackson et al., 2010). Similar ridge-crest boundary currents affecting regional dispersal have been observed in the northeastern Pacific along the Juan de Fuca Ridge (Cannon et al., 1991; Cannon and Pashinski, 1997; Helfrich et al., 1998). Characterized by an intermediate spreading rate, this ridge has a relatively shallow median valley. As a result, near-bottom dispersal is topographically constrained in the along-valley direction (Thomson et al., 2003; Veirs et al., 2006), similarly to the rift valley of the MAR. Plumes from high-temperature vents rise above the ridge topography where dispersal by oceanic currents is not directly constrained by topographic blocking (Baker and Massoth, 1987), similarly to the EPR.

Hydrothermal sources also occur on volcanically active seamounts and along submarine slopes of island volcanoes, where topographic blocking constrains near-source horizontal dispersal along- and down-slope. Observed velocities over seamounts (Eriksen, 1991) and in saddles on seamount chains (Thurnherr and St. Laurent, 2011) are often significantly elevated compared to the open ocean, with important implications for 
dispersal. Rectification of oscillatory background flows, e.g., due to the passage of mesoscale eddies, can drive closed circulation cells around the crest and upper flanks of isolated seamounts and are sometimes inferred to help retain propagules in their vicinity (Lavelle and Mohn, 2010). Conversely, isolated seamounts and islands in strong cross-flows can shed vortices that increase dispersal by stirring background gradients.

The spatial separation between vent fields often is invoked as a potential barrier to larval connectivity, but it is important to recognize that dispersal time (not distance) and its magnitude relative to larval time scales (e.g., precompetency period or pelagic larval duration) is the critical metric. Any discussion of dispersal barriers needs to include an evaluation of physical transport dynamics (including variability imposed by tides and seasons), and larval time scales, many of which are speciesspecific. The examples above demonstrate that there are many ways for seafloor topography to facilitate, rather than restrict, dispersal.

Within the context of metacommunity modeling, the relevant dispersal timescales typically span many days to months and in a few cases years (see section Range of Capabilities for Planktonic Dispersal). On these timescales, the effects of most oceanic dispersal processes can be encoded in dispersal kernels (the distributions of larval destination locations), which quantify connectivity between larval-source and colonization sites. Often, only horizontal dispersal is considered because the typical length scales of vertical dispersal due to turbulent mixing does not exceed tens of meters on such time scales. In addition to physical dispersal processes in the ocean, the dispersal kernels can also include effects of active larval transport, such as swimming and buoyancy regulation. Dispersal kernels can be constructed from numerical models of the oceanic circulation, possibly augmented with biological components, and/or from oceanographic observations (Mitarai et al., 2016). Provided sufficient supporting information is available, dispersal kernels can be constructed for any region of the ocean and for any organism. While dispersal kernels are expected to be regionspecific, many chemosynthetic organisms occur primarily or exclusively at hydrothermal vents or hydrocarbon seeps, both of which are associated with specific topographic settings, allowing some generalization.

Dispersal patterns of vent species influenced by bottom currents and topography may connect vent populations heterogeneously, resulting in a set of highly connected hub populations. Under such circumstances, loss of key populations due to disturbances may lead to a system-wide metapopulation failure (Watson et al., 2011). Furthermore, physical connectivity of vent populations should be inherently stochastic, driven by mesoscale and sub-mesoscale eddies. Eddies are ubiquitous, even at great ocean depths, and necessarily make larval transport trajectories highly variable and unpredictable (Adams et al., 2011; Mitarai et al., 2016). The stochastic nature of connectivity may promote species coexistence by making dispersal patterns of less competitive species uncorrelated from those of competitors (Siegel et al., 2008; Berkley et al., 2010). To assess dispersal influence on persistence and diversity of vent species, metacommunity models must account for both stochasticity and heterogeneity in population connectivity of key species.

Some vent larvae may disperse high in the water column, where their dispersal patterns are less constrained by bottom topography (Pond et al., 2000; Dittel et al., 2008). They can be transported over greater distances by shallower, directional ocean currents (e.g., deep penetration of western boundary currents). Given quantitative information about larval development and behavior, coupled physical-biological models should be able to characterize species-specific connectivity patterns, both on intraand inter-regional scales (Thomson et al., 2009; McGillicuddy et al., 2010; Mitarai et al., 2016) For instance, one such model suggested that the South Equatorial Current could bridge the entire southwest Pacific vent complex with strong directionality (e.g., migration from the Lau to Manus Basins; Mitarai et al., 2016). Similarly, vent fields in the Okinawa Trough and the Izu-Bonin Arc may be connected by the Kuroshio Current. It is estimated that interregional (e.g., basin-to-basin) connections should occur infrequently, once in tens to hundreds of thousands of years (Mitarai et al., 2016). While quantifying connectivity on interregional scales (e.g., between vent fields in distant basins) is valuable for understanding gene flows of vent-restricted animals on evolutionary time scales, such information may be difficult to interpret in terms of metacommunity dynamics on ecological (months to years) time scales (but see section Genetic Approaches to Metacommunity Dynamics on Ecological Time Scale).

\section{Effects of Long-Distance Dispersal on Metacommunity Dynamics}

Field studies in vent systems show the potential for limited larval dispersal distances (local retention on scales of kilometers or less), but also provide evidence for occasional long-distance events. These data are limited, as measuring dispersal of marine larvae is difficult and particularly challenging in the remote deep sea. Approaches used in coastal environments for direct tracking of larvae, such as visual follows, mark and recapture studies, analysis of naturally occurring geographically specific chemical tags, or genetic parentage analyses, have not yet been applied to vent systems. Most of the evidence for shortdistance dispersal is indirect, coming from interpretations of larval abundances in the water (Metaxas, 2004; Mullineaux et al., 2005), analyses of circulation patterns (Thomson et al., 2003) and coupled bio-physical models (McGillicuddy et al., 2010). The mechanisms limiting dispersal on ridges in the eastern Pacific appear to be a combination of transport constraints induced by topographically-steered flows and vertical swimming behaviors of the larvae (e.g., Mullineaux et al., 2013).

In contrast, the evidence for long-distance dispersal comes from laboratory studies of larval physiology, field investigations of colonization, and molecular genetic analysis of field samples. Experiments on the metabolism and energy stores of larvae of the giant vent tubeworm Riftia pachyptila indicate that this species has the potential to disperse distances of a $100 \mathrm{~km}$ or more (Marsh et al., 2001) in typical ridge-aligned currents. A fortuitous observation of colonization of vents on the EPR 
after a seafloor eruption by the limpet Ctenopelta porifera, whose closest known source population was over $350 \mathrm{~km}$ away (Mullineaux et al., 2010), indicates that dispersal over very long distances, although rare, is possible. The physical transport mechanisms responsible for such long-distance dispersal may include deep currents that interact with ridge topography (Lavelle et al., 2010) or mesoscale eddies (Adams et al., 2011). Additional support for episodic long-distance dispersal comes from molecular genetic analyses that reveal instances of low genetic variation between geographically separated populations (see review in Vrijenhoek, 2010). This approach is examined in more detail in section Genetic Approaches to Metacommunity Dynamics on Ecological Time Scale.

The capability for long-distance dispersal may be considered a species trait, as it is constrained by behavior and planktonic larval duration, but the realized dispersal distances of individual larvae within a species cover a broad range. This distribution of larval destination locations is the dispersal kernel (section Physical Transport and Ecological Connectivity). Models of populations and communities have shown that a distribution of dispersal distances, and not just the mean dispersal distance, is essential for explaining recruitment patterns, range expansion rates, genetic structure, and metapopulation dynamics (reviewed in Levin et al., 2003). In both terrestrial and marine ecosystems, most propagules move short distances away from the source, making long-distance dispersal events rare (Trakhtenbrot et al., 2005), although possibly more prevalent in marine systems (e.g., Kinlan and Gaines, 2003). This pattern results in dispersal kernels with long tails, and those tails have important implications for metacommunity properties such as succession and resilience to disturbance.

The tails of dispersal kernels in deep-sea vent systems are prohibitively difficult to measure, but insights may be gained from theory. It is well known that long-distance dispersal can increase metapopulation survival, as dispersers provide a rescue effect that counteracts local extinctions (reviewed in Briggs and Hoopes, 2004). If, however, dispersal is sufficient to synchronize dynamics of the subpopulations, it can lead to large system-wide fluctuations and no longer acts as an effective stabilizer. These opposing effects of dispersal contribute to complex metapopulation dynamics (Abbott, 2011), but there is often an intermediate dispersal optimum that bolsters overall metapopulation growth. Similarly, local extinction rates appear to play a role, as long-distance dispersal may increase metapopulation survival when local extinction probabilities are intermediate (Bohrer et al., 2005). Experimental studies provide evidence for stabilizing, destabilizing or neutral effects of dispersal on metapopulation dynamics (reviewed in Wang et al., 2015).

These counter-intuitive effects of dispersal on metapopulation dynamics raise intriguing questions about how long-distance dispersal in vent ecosystems may influence recruitment and succession at individual sites, and overall diversity and resilience of regional metacommunities. For modeling studies, the interactions between probabilities of long-distance dispersal and disturbance may produce interesting and non-intuitive patterns of metapopulation dynamics. Species interactions, such as facilitation or competition, between long-distance colonists and later arrivers during post-disturbance colonization may then influence species composition at individual sites and diversity in the metacommunity, particularly if the dispersers trigger alternative states at disturbed sites. Understanding these dynamics from a theoretical perspective allows for a more informed interpretation of field observations, particularly of post-disturbance succession and regional diversity, and an improved capability to predict resilience to both natural and human disturbance (e.g., Trakhtenbrot et al., 2005).

\section{Regional and Local Influences on Succession}

At deep-sea hydrothermal vents, primary succession-the nonseasonal, directional continuous pattern of colonization and extinction (Begon et al., 1990) - is typically initiated by formation of new, unoccupied habitat, such as from lava flow caused by volcanic eruptions. These major disturbance events, as well as subsequent changes in vent fluid flow that affect habitat quality, shape metacommunities at some deep-sea hydrothermal vents. In the framework of succession, metapopulation and metacommunity concepts (Leibold et al., 2004; Logue et al., 2011) are manifested as local (within/between species and their environment) and regional (dispersal) controls on species distributions through time, as illustrated in Figure 1.

Vent primary succession has been observed along the fastspreading $9^{\circ} 50^{\prime} \mathrm{N}$ EPR in 1991 and 2006, and at the intermediatespreading Juan de Fuca Ridge (JFR) on Axial Volcano in 1998 and on Co-Axial Segment in 1993. On the EPR, within 5 years of each eruption, rapid and sequential colonizations were observed from white bacterial mats, to the small siboglinid tubeworm Tevnia jerichonana, to the giant tubeworm Riftia pachyptila, and to the mussel Bathymodiolus thermophilus (Shank et al., 1998; Fornari et al., 2012). The transition from Tevnia to Riftia appears to correspond to waning vent fluid flux but may also be influenced by biogenic settlement cues (Mullineaux et al., 2000; Sievert and Vetriani, 2012). The mussels are slower to get established, but once they reach adult size and high densities, may reduce the hydrogen sulfide available for tubeworms. Also within 5 years, the macrofauna and meiofauna had reached $40-70 \%$ of their pre-eruption species richness (Shank et al., 1998; Gollner et al., 2015). Following the 2006 eruption, both the macrofaunal and meiofaunal communities showed a shift in species composition over time (Mullineaux et al., 2010, 2012; Gollner et al., 2015).

After volcanic eruptions at the JFR, grazing polychaetes colonized new vents, followed by the tubeworm Ridgeia piscesae. The tubeworm-associated macrofauna sequentially changed in dominance from polychaetes to limpets and total faunal richness at vent sites recovered to $75-90 \%$ of pre-eruption values within 2 years, representing $30-60 \%$ of species from the larger regional species pool (Tunnicliffe et al., 1997; Marcus et al., 2009; Gollner et al., 2017). Notably, during the short observation periods after the eruptions in both Pacific regions, death of foundation species in small aggregations resulted from cessation of vent flow. These observations point to the high temporal variability of venting and community structure on faster-spreading centers 
(Tsurumi and Tunnicliffe, 2001; Gollner et al., 2013; Klose et al., 2015; described further in section Global Patterns of Vent Distributions, Disturbance Frequency and Longevity; Figure 3).

Temporal changes in species composition at sites not disturbed by recent eruptions tend to be modest, except when venting ceases. Long-term studies at the Logatchev and Lucky Strike sites on the Mid Atlantic Ridge that experience volcanic eruptions on millennia time scale (Perfit and Chadwick, 1998) revealed rather stable mussel assemblages over 10-14 years of observations with small-scale variations in community composition related to changes in fluid flow (Gebruk et al., 2010; Cuvelier et al., 2011; Sarrazin et al., 2015). At Juan de Fuca Ridge, directed changes in community composition from polychaetes (Paralvinella sulfincola and P. palmiformis) to limpets (Lepetodrilus fucensis) to tubeworms (Ridgeia piscesae) over 4 years were related to both changes in fluid flow and associated interactions, appearing to follow a dynamic succession model that allows reversal with changes in fluid flow (Sarrazin et al., 1997). Non-vent endemic deep-sea species appeared in patches where venting subsided (Podowski et al., 2010; Sen et al., 2014).

Changes in community composition after eruptive disturbances coincide with changes in fluid flow conditions. At fast-spreading centers, hydrothermal fluid flux typically wanes within a few years after an eruption (Shank et al., 1998; Le Bris et al., 2006) and species diversity tends to increase (Mullineaux et al., 2012; Gollner et al., 2015). Under these conditions, it can be difficult to distinguish between effects of changing environmental conditions and biological succession. The influence of species interactions, however, are very clear in cases when foundation species provide complex physical structures that enhance the surface area and the range of chemical regimes (e.g., warmer hydrothermal fluid at the base of giant tubeworm clusters, and more moderate and cooler regimes at the top) potentially facilitating colonization of other species and playing an important role in succession (Sarrazin et al., 1997; Govenar and Fisher, 2007; Kelly and Metaxas, 2008; Marcus et al., 2009).

Manipulative colonization experiments that mimic disturbance by providing new substratum have proven useful at EPR vents for investigating biotic processes such as facilitation, inhibition and predation. Colonization surfaces exposed for overlapping intervals showed that early mobile colonizers at active vents may inhibit later colonists whilst sessile colonizers may facilitate settlement of later colonists (Mullineaux et al., 2003). Inhibition by grazing or predation was more prominent in areas of high fluid flux, productivity, and faunal densities, whilst facilitation was stronger in areas of low temperatures, productivity, and densities (Micheli et al., 2002; Mullineaux et al., 2003). Competitive exclusion or changes in larval supply may have led, for example, to replacement of the pioneer limpet Lepetodrilus tevnianus by its congener $L$. elevatus unrelated to changes in fluid flow (Mullineaux et al., 2012; Gollner et al., 2015).

Regional controls in the form of larval supply strongly influence primary succession because they determine which species are first to arrive and become established. Larval supply of some species appears to be relatively continuous, but others arrive only episodically, hence we are unable to predict timing of recovery after a disturbance (Adams and Mullineaux, 2008; Mills et al., 2013). For instance, the arrival of a pioneer limpet Ctenopelta porifera after the 2006 EPR eruption was completely unexpected, yet had a strong and persistent effect on communities at both disturbed and near-by undisturbed vents
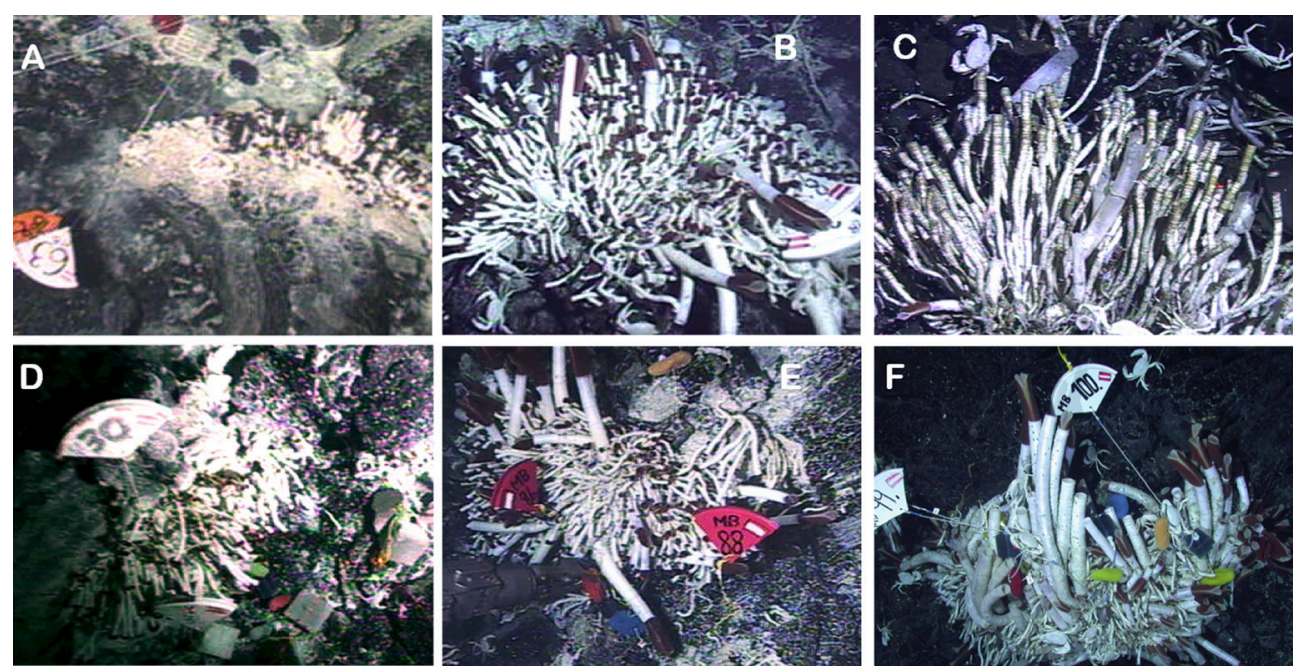

FIGURE 3 | Succession of vent communities after the volcanic eruption at the $9^{\circ} 50^{\prime} \mathrm{N}$ East Pacific Rise in 2006 . (A-C) at P-Vent: Small patches of tubeworms Tevnia jerichonana 1 year posteruption (A) changed into a mixed T. jerichonana and Riftia pachyptila community 2 years posteruption (B), to mostly dead tubeworms due to ceased vent fluids 4 years posteruption (C). (D-F) at Tica site: Patches of T. jerichonana 1 year posteruption (D) sequentially changed into a mixed T. jerichonana and $R$. pachyptila community $\sim 2$ years posteruption (E), and to a mixed $R$. pachyptila and T. jerichonana community 4 years posteruption (F). Permission to re-use material from Klose et al. (2015). 
in the region (Mullineaux et al., 2012). Limited larval supply may delay recovery even after benthic habitats have transitioned to conditions that favor later-successional species (Mullineaux et al., 2010; Mills et al., 2013). Meiofauna succession at the EPR was consistent with dispersal potential. Copepod species with great pelagic dispersal capabilities and high genetic connectivity demonstrated rapid recovery (Gollner et al., 2016), whereas nematode species lacking pelagic dispersal stages demonstrated slow recovery (Gollner et al., 2013).

Observations of vent succession suggest complex recovery dynamics in metacommunities, with species differing in their dispersal ability and with successful colonizers outcompeting poor competitors. Abiotic controls constrain the change of hydrothermal fluid conditions through time, thus determining the presence or absence of symbiotic foundation species that can be mobile (snails, mussels), or sessile (tubeworms). These species strongly influence the physical structure at vents and themselves modify the abiotic environment for the associated fauna.

\section{Genetic Approaches to Metacommunity Dynamics on Ecological Time Scales}

Genetic diversity and connectivity of hydrothermal vent animal populations have been studied at various spatial scales along the global mid-ocean ridge and arc-backarc systems. The studies have led to a series of discoveries of common or varying geographical subdivisions among diverse vent taxa, which, in turn, have deepened our understanding about the effect of several environmental (e.g., geomorphology of oceanic ridges, spatial and temporal stability of vent habitats, and deep-sea currents) and biological (e.g., species-specific life histories, larval duration, motility and behavior) factors on the connectivity of vent metapopulations (reviewed in Vrijenhoek, 2010). Population connectivity and genetic diversity are influenced by historical factors such as vicariance, range and/or demographic expansion through dispersal, and introgressive hybridization (backcrossing of an interspecific hybrid with one of its parent species), both in mid-ocean ridge and arc-backarc systems (Young et al., 2008; Plouviez et al., 2009; Johnson et al., 2014; Yahagi et al., 2015; Zhang et al., 2015; Jang et al., 2016).

Population genetics have been widely used to infer the spatial extents of vent metapopulations through the detection of patterns of genetic differentiation and structure. In the EPR and the Gorda and Juan de Fuca ridge systems, extrinsic factors, such as discontinuities of oceanic ridges, their associated hydrographic features, as well as the spatial and temporal patchiness of vent habitats, appear to be some of the most important influences on genetic connectivity at regional scales. Within segments along the EPR, there is relatively low genetic differentiation among populations, even those separated by distances of more than a $100 \mathrm{~km}$ (Vrijenhoek, 2010; Coykendall et al., 2011; Jang et al., 2016; but see Matabos et al., 2008b). The apparent genetic homogeneity among some populations within segments is consistent with the long-distance larval dispersal potential of many vent species (Marsh et al., 2001; McGillicuddy et al., 2010).

In the western Pacific area, hydrothermal vent fields are located in discontinuous arc and backarc basin systems. In these settings the patterns of genetic structure of metapopulations are species-specific. For some species, significant genetic structuring occurs among populations from different basins due to limited larval transport (Mitarai et al., 2016), but for some others this structuring is less pronounced or non-existent, probably due to differences in reproductive strategies (Kumagai et al., 2015). Populations of Neoverruca barnacles, Shinkailepas limpets and alvinocaridid shrimps on volcanic arcs show lower genetic diversity than those in backarc basins (Watanabe et al., 2005; Yahagi et al., 2015, 2017), whereas the diversity in populations of Bathymodiolus mussels is comparable between backarc basin and mid-ocean ridge systems (Breusing et al., 2015).

Populations in backarc basins are occasionally connected to methane seep populations. For example, Calyptogena clams and Shinkaia squat lobsters show significant genetic structuring between methane seep and hydrothermal vent field populations, whereas no structuring has been observed in Lamellibrachia tubeworm and Bathymodiolus mussel populations (Watanabe et al., 2010; Shen et al., 2016; Yang et al., 2016). Recent genome-wide analyses of $B$. platifrons revealed differentiation between methane seep populations the in South China Sea and hydrothermal vent populations in the Okinawa Trough (Xu et al., 2017). Population differentiation among barckarc basins has been also discovered in three basins, Manus, North Fiji, and Lau in species of the family Provannidae (Thaler et al., 2011).

Population genetics also provide powerful tools to estimate parameters relevant to hydrothermal vent metapopulations dynamics on ecological timescales. These parameters include the rate and directionality of migration among populations and effective population sizes. Estimating directionality and rate of migration is important for revealing the magnitude of connectivity and potential source-sink relationships within metapopulations. Greater migration rates and symmetrical directionality would render a metapopulation more resilient to localized disturbances. Estimating effective population sizes is also important for understanding the resilience of metapopulations because genetic diversity is proportional to effective population size. A sufficiently large and well-connected metapopulation would have great genetic diversity, which would translate into a greater capacity of adapting to environmental changes, thus enhancing resilience.

Traditional estimates of genetic connectivity relied on the estimation of the number of migrants between populations $\left(N_{e} m\right)$ using the relationship described by Wright's island population model equation $F_{\mathrm{ST}}=1 /\left(4 N_{e} m+1\right)$, where $F_{\mathrm{ST}}$ is an index of genetic differentiation, $N$ the effective population size, a number of individuals contributing to reproduction, and $m$ the migration rate (Wright, 1951). The island model is similar to a metapopulation model in that it assumes a set of spatially distinct populations connected via dispersal. In the island model, populations are assumed to have reached an equilibrium between genetic drift (diverging force) and non-directional migration (unifying force), while their sizes remain equal and constant. Because $F_{S T}$ can be calculated from differences in allelic frequencies at individual loci, it has been widely used to make estimates of gene flow (as $N_{e} m$ ) in vent metapopulations (see Vrijenhoek, 2010). However, this 
approach has been heavily criticized due to: (1) the many unrealistic underlying assumptions of the island model; (2) the non-equivalence between molecular markers of species with different histories; (3) the difficulty in interpreting $N_{e} m$ values due to the non-linear relationship with $F_{S T}$; and (4) the long times needed for populations to reach equilibrium conditions (hundreds to thousands of generations depending on $N_{e}$ and $m$ ), which make it difficult to interpret gene flow $\left(N_{e} m\right)$ in the context of connectivity at ecological time scales of a few generations (Broquet and Petit, 2009; Hellberg, 2009; Lowe and Allendorf, 2010, and references therein).

Modern approaches integrating coalescent theory (Kingman, 1982) and Bayesian statistics overcome many of the issues related to the use of $F$-statistics to infer connectivity. Coalescent approaches, which exploit information from gene-genealogies, allow for testing more realistic models of metapopulation connectivity through the simultaneous estimation of directional migration rates, effective population sizes, and temporal population size changes (Beerli and Felsenstein, 2001; Beerli and Palczewski, 2010). For example, Young et al. (2008) found a general southward pattern of migration along the northeast Pacific system, and larger effective population sizes of the siboglinid tubeworm Ridgeia piscesae in the southern populations compared to those in the north. Coalescent approaches have also been implemented to measure long-term migration rates in mollusk and polychaete species along the EPR (Plouviez et al., 2009, 2010, 2013), crustacean and mollusk species in the Indian Ocean ridges (Thaler et al., 2011; Beedessee et al., 2013; Chen et al., 2015), alvinocaridid shrimp from the MidCayman Spreading Center (Plouviez et al., 2015) and the Mid-Atlantic Ridge (Teixeira et al., 2012, 2013). Despite the evident advantages of coalescent approaches over traditional $F$ statistics, the migration estimates obtained through many of these approaches are considered long-term because of necessary equilibrium assumptions over the last $\sim 4 N_{e}$ generations (i.e., average time to coalescence).

Bayesian assignment approaches (Wilson and Rannala, 2003; Piry et al., 2004; Faubet and Gaggiotti, 2008) allow the estimation of contemporary directional migration rates (within the last one or two generations), and thus have gained popularity in understanding population and community connectivity at ecological time-scales. These approaches exploit the power of multilocus genotypes to estimate migration rates among populations without the need for equilibrium assumptions. For example, Zhang et al. (2015) found that the Southern East Pacific Rise (SEPR) populations of the siboglinid tubeworm Tevnia jerichonana appear to be a mix of first and second generation immigrants from the Pacific Antarctic Ridge (PAR) and SEPR non-migrants, whereas the Northern EPR and the PAR populations seem to be mainly composed of non-migrant individuals.

Bayesian assignment approaches have also recently been utilized to infer population migration rates in alvinocaridid shrimp along the MAR (Teixeira et al., 2012) and western Pacific backarc basins (Thaler et al., 2014), alvinellid polychaetes from the eastern Pacific ridges (Jang et al., 2016), bathymodiolin mussels from the Indo-Pacific (Breusing et al., 2015) and the
MAR (Breusing et al., 2016), and lepetodrilid limpets from the Scotia Sea (Roterman et al., 2016). Migration rate estimates are most accurate and precise when true migration rates among populations are moderate $(m<0.333)$, population structuring is significant, and sampling of individuals and loci is substantial (Faubet et al., 2007; Meirmans, 2014).

The use of next-generation sequencing approaches (e.g., Herrera et al., 2015a) to generate multilocus datasets in vent taxa (e.g., Reitzel et al., 2013; Herrera et al., 2015b) promises to drastically improve the statistical power to estimate rates of directional migration and other parameters contributing to vent metacommunity dynamics. Estimation of effective population size is also improved by next-generation sequencing, as singlesample genomic methods based on linkage disequilibrium are being actively developed and implemented to this end (Wang, 2016). Interestingly, this parameter of effective population size has shown strong correlation with that age at maturity and adult lifespan (Waples et al., 2013), thus offering an opportunity to increase our understanding of biological traits that are relevant to population dynamics.

\section{Dispersal Effects on Regional Species Diversity}

The distinctive nature of hydrothermal vents linked to spreading ridges and volcanic arcs leads to regionalized faunas with strong links to plate tectonic history (Tunnicliffe and Fowler, 1996). The expanses of hostile "matrix," separating potential vent habitats that are tied to plate boundaries, can be vast (e.g., the Pacific Plate); thus, analyses of taxonomic distinctness identify biogeographic regions with very high endemism at the species level (Moalic et al., 2012). The probability that pelagic larvae can transcend the distance barrier is low (Mitarai et al., 2016). However, a few species do span large distancesperhaps with teleplanic (far-dispersing) feeding larvae. Such connectivity is particularly important when a species with a wide range is a key component of the trophic web or is a habitat forming, foundation species. For example, the range of the alvinocaridid shrimp Miricaris fortunata, an important microbial consumer with high biomass, spans from $4^{\circ} \mathrm{S}$ to $38^{\circ} \mathrm{N}$ on the mid-Atlantic Ridge, transcending transform faults and non-venting regions. Species of the mussel Bathymodiolus can transcend biogeographic provinces (Breusing et al., 2015) and chemosynthetic habitats (Miyazaki et al., 2013). Vent community assembly can be driven by these foundation species (Van Dover, 2002), thereby influencing species sorting.

The regional scale can encompass extensive linear features of mid-ocean ridges or more complex tectonic arrangements in back-arc spreading centers and associated volcanic arcs. At this scale, tectonic character and magmatic budgets may vary, creating distinctly different hydrothermal habitats. While chemical composition of mid-ocean ridge fluids is usually controlled by interactions with underlying basalts, in arcback systems, the subducting slab has a complex influence on circulating hydrothermal fluids as it supplies sediments, water and organic carbon to the subduction zone (Stern et al., 2013). Fluids can be enriched in ammonia and volatiles $\left(\mathrm{SO}_{2}\right.$, 
$\mathrm{CO}_{2}, \mathrm{CH}_{4}$ ) especially in volcanic arcs while reduced in iron and manganese compared to MOR fluids (Gamo et al., 2006; Butterfield et al., 2011). The availability and nature of reduced compounds will influence the autotrophic base of the food chain while fluid character will affect habitat suitability. Regional community diversity should be affected because of the high within-region variability in fluids and magma supply (e.g., Mottl et al., 2011); however, evidence is accumulating slowly due to limited fieldwork. For example, chronic eruptive activity on NW Rota (Mariana Arc) results in a very limited vent community of a few wide-dispersing species (Embley et al., 2006), while other volcanoes in the arc foster communities that differ from site to site due to dominant fluid and substratum characteristics (Tunnicliffe et al., 2009; Stevens et al., 2015). Nearly none of the species at the Mariana-Izu-Bonin arc vents occur in the adjacent Mariana back-arc (Kojima and Watanabe, 2015). Depth barriers to dispersal may be a factor at the extremes (3,900 vs. $180 \mathrm{~m})$, but there is depth overlap around $1,600 \mathrm{~m}$. These settings provide useful tests of the roles of regional flow dynamics and of habitat suitability to moderate the arrival and recruitment of larvae.

Within a region, connectivity is related to the distance between suitable vent habitats (Figure 4). Stepping-stone connections are evident in many species (Vrijenhoek, 2010), but species turnover along the range may result in functional substitutions at distal sites. For example, in the Northeast Pacific, the limpet Lepetodrilus fucensis dominates relative abundance of most vent communities on the Juan de Fuca Ridge (Tsurumi and Tunnicliffe, 2003), but its role in a very similar assemblage is filled by Lepetodrilus gordensis on Gorda Ridge, separated by the Blanco Transform Fault (Johnson et al., 2006). Community compositional shift may also be a function of changes in environmental conditions along a tectonic feature (e.g., variable volcanicity or a cline in sulfur speciation). Teasing out components of species sorting from those of dispersal is a challenge (Legendre et al., 2005).

The realized dispersal of individual species will affect beta (across-site) diversity in the region. Distance and lack of habitat may restrict shorter-range species to vent sites within a segment and possibly between adjacent segments, whereas other species can transcend barriers such as depth changes and non-venting segments (Figure 4). Frequency of suitable habitat will also drive diversity both between and within sites because both number of sites and overall habitat area is affected (as in an island archipelago, Cabral et al., 2014). Baker et al. (2016) mapped effluent from low temperature venting and proposed that such habitat on spreading ridges is notably more prevalent than currently mapped. Therefore, metacommunities encompassing species with low dispersal may have greater exchange than currently assumed. However, vent habitats are not equally represented along a tectonic feature. Low temperature venting does not include the complex communities of black smoker chimneys (Sarrazin and Juniper, 1999; Cuvelier et al., 2011). Thus, habitat suitability and stability will regulate recruitment and, ultimately, connectivity. Vent habitat stability is reflected in the mass accumulation of polymetallic sulfides; large deposits of ages 1,000-10,000 s years (Jamieson et al., 2014) forming complex habitat which allows for species accumulation over an extended period.

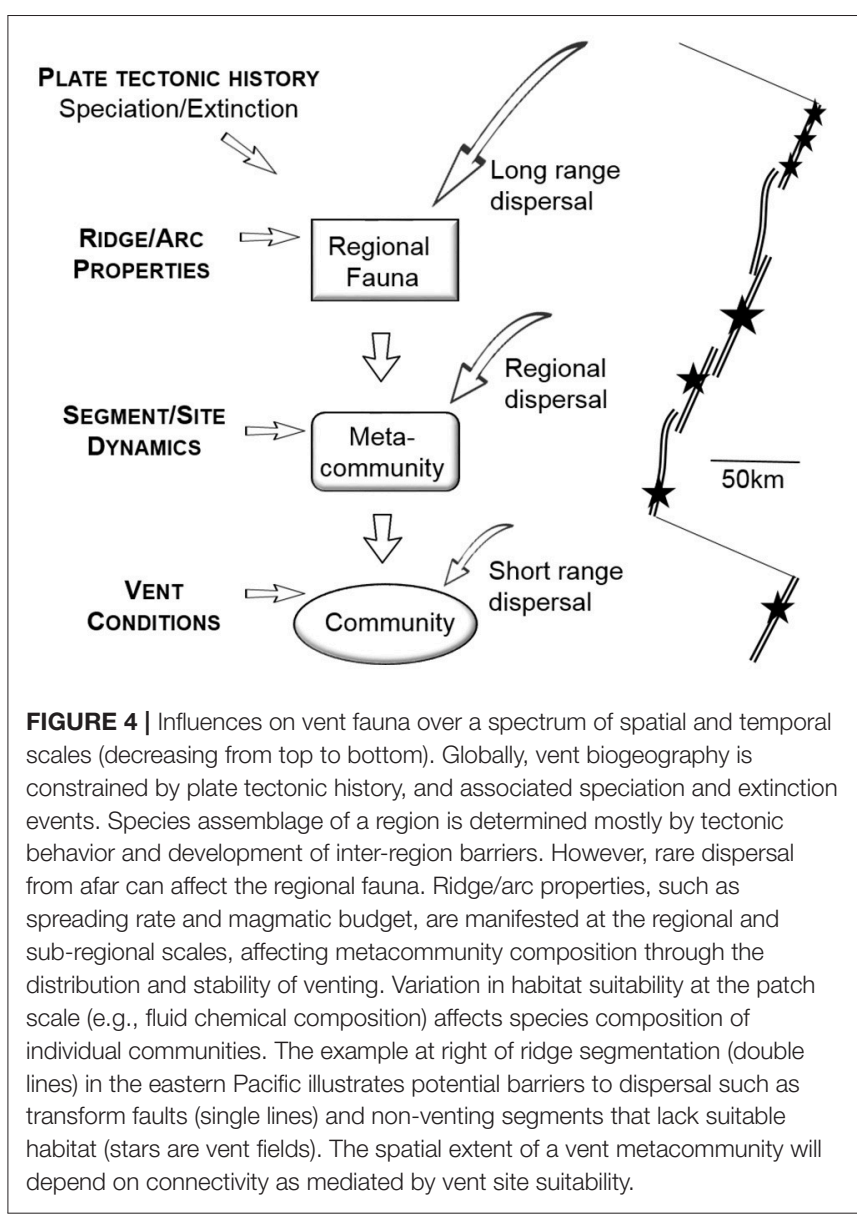

The spatial extent of a vent metacommunity is likely strongly influenced by dispersal barriers and dispersal potential of component species. Species ranges do not necessary coincide, so community composition along a discrete geologic feature (ridgecrest, arc) is expected to be a cline of overlapping ranges. Communities in the center of such a feature tend to have higher alpha (within-site) diversity than those at the ends (Colwell et al., 2004). However, if dispersal on ecological time scales from outside the region/feature occurs predominantly at one end of the range, it may skew the diversity pattern. Habitat suitability must also play a large role in community assembly and dynamics. For example, at Axial Volcano on the JFR, although larval supply of the limpet Lepetodrilus fucensis did not appear to be limiting across space or time (Metaxas, 2004), the species dominated the community in a particular sequence of species interactions (Marcus et al., 2009). As for the regional setting, the spatial extent of a species' range is also determined by a combination of dispersal and suitable habitat distribution.

\section{Seeps as a Contrast to Vents}

Methane seeps are chemosynthetic ecosystems bearing remarkable similarity to hydrothermal vents, while exhibiting important differences that would be expected to alter metacommunity dynamics. Like vents, seeps occur where fluids rich in reduced compounds are expelled into the deep 
ocean from beneath the seafloor, resulting in productive ecosystems fueled by sulfide, methane, and hydrogen oxidation (Levin, 2005). A key difference is the relatively lower rate of delivery of reduced compounds at seeps. Faults, conduits, and permeable sediments contribute to dendritic conduit systems, such that fluid flow is focused into discrete locations where patchy seep habitats are located (Hornbach et al., 2007), often surrounded by "background" sediments and fauna, typical of regional non-chemosynthetic habitats.

Ecosystem differences suggest cold seeps may experience less frequent or impactful environmental disturbances than many hydrothermal vents, at least those in dynamic geological settings (e.g., eastern Pacific). Seeps and their communities are thought to persist for centuries or longer (Cordes et al., 2009), making sudden extinctions within patches in the metacommunity less likely. Hydrogen sulfide, produced through anaerobic oxidation of methane (AOM) (Boetius et al., 2000), may vary among seep habitats and strongly influences faunal composition. Smallscale heterogeneity in sediment geochemistry seems to be closely linked to faunal patterns, and considered a primary factor regulating seep faunal communities (Sahling et al., 2002; Cordes et al., 2010). Fine-scale chemical gradients in sediments may even facilitate evolutionary radiations, such as for co-occurring dorvilleid polychaete species in the Northeast Pacific, which show extreme dietary niche differentiation (Levin et al., 2013).

Sulfide is widespread in non-seep organic-rich sediments on margins, and many background species adapted to these conditions can occur at weakly seeping sites (Bell et al., 2016). Consequently, changes to geochemical gradients may be less disruptive for seep communities than fluid flow alterations are for vent communities. Unsurprisingly, half or more of the species in seep infaunal communities may be common to background habitats, and many background predators forage at seeps (reviewed in Levin et al., 2016a). The longevity of seepage at individual sites plus linkages to background megafauna could increase connectivity among metacommunity patches, including non-chemosynthetic communities.

Other differences between vent and seep settings may result in higher dispersal potential and metapopulation connectivity at seeps, which would impact metacommunity structure. The geographic distribution of methane seeps largely follows continental margins, and sites tend to be shallower than vents, facilitating larval dispersal via along-slope boundary currents, topographic waves, and proximity to productive surface waters (in the case of planktotrophic groups). Vertical larval transport in the buoyant seep bubble plumes may also enhance dispersal. Worldwide estimates of the number of seeps have been revised upwards to the tens of thousands, largely due to the ability to detect seepage with bubble plumes (Skarke et al., 2014) and oil slicks (MacDonald et al., 2015). Individual seeps are often clustered at the scale of kms (e.g., Sahling et al., 2008), likely enhancing the probability of seep detection by settling larvae. Individual seeps can also be spatially extensive relative to hydrothermal vent fields (Skarke et al., 2014), possibly augmenting connectivity and diversity. Species evolving in seep settings may have long larval lifespans, slower growth/greater longevity, or ability to settle at sulfidic sediments.
While seeps and vents share many faunal genera that rely on unique habitat chemistry, including those of symbiont-hosting mussels, tubeworms, and clams, only a limited number of species cross between systems (Tunnicliffe et al., 2003). However, the existence of hybrid habitats sharing seep and vent characteristics (e.g., Jaco Scar, Costa Rica, Levin et al., 2012; serpentinite vents, Kelley et al., 2005) could promote connectivity, such as for Amphysamytha fauchaldi, which is found at Guaymas Basin sedimented vents in addition to distant cold seeps (Stiller et al., 2013). Kiel (2016) suggests that sedimented vents represent an evolutionary link between vents and seeps, and there are more generic similarities between vents and seeps in the Pacific than Atlantic Ocean, perhaps because sedimented vents are more common along active margins in the Pacific Ocean (e.g., Manus Basin, Gorda Ridge, Middle Valley, Guaymas Basin).

Cold seeps typically occur in soft sediment settings, but carbonate precipitation associated with AOM eventually creates hard substrata, which contain their own unique faunal assemblage (Levin et al., 2015). In short-term ( $\sim 1$ year) colonization and transplant experiments, carbonate assemblages of colonists responded strongly to geochemical heterogeneity and colonists resembled late successional assemblages on seep carbonates in Costa Rica and Oregon, suggesting strong niche processes (Grupe, 2014; Levin et al., 2017). At peripheries of seeps with lower influence from sulfide and methane, macrofaunal colonization of carbonates can be slower and more stochastic than at the center of the seep (Gaudron et al., 2010; Grupe, 2014). Sediment colonization experiments (Levin et al., 2006) and community surveys (Sahling et al., 2002; Levin et al., 2015) have also found that species composition of seep faunas tends to correspond to physicochemical conditions (sulfide, oxygen, substrate type), highlighting the importance of niche-based regulation of metacommunities.

Seep environments provide an interesting comparison to hydrothermal vents in terms of metacommunity dynamics. Like vents, the presence and composition of the fluid plays an important role in determining patch quality. The greater spatial extent of habitats, expanded bathymetric range, and wider distribution of seeps allow for greater connectivity. However, relative to many vents, seeps have lower frequency of disturbance and a greater similarity of some environmental characteristics to the surrounding deep sea, allowing for species interactions to play out for decades and possibly for climax communities to develop. This may result in differences in the relative importance of regional to local processes in regulating metacommunities between vents and seeps.

\section{SYNTHESIS OF FIELD OBSERVATIONS AND KEY QUESTIONS}

The field observations described in section Field Observations and Synthesis illustrate the types of data available to inform metacommunity analyses at hydrothermal vents. One of our main goals is to evaluate what analyses are sufficiently supported by the observations, and what additional data are needed to fill critical gaps. Although observations exist for all general processes 
identified as particularly important for vent systems, the information on most individual topics is far from comprehensive, and is gathered largely from the more easily accessible regions in the eastern Pacific (EPR and Juan de Fuca Ridge), the northern Atlantic (Mid-Atlantic Ridge), and, most recently, the western Pacific (Lau and Mariana regions). One notable exception is the map of vent locations, which includes sites from across the globe, including the southern Atlantic, Indian and Southern Ocean, and Arctic seas. The correspondence between spreading rate at plate boundaries, which is well constrained by geological observations and theory, and key features such as vent spacing and disturbance rates, provides a useful tool for estimating those values even in locations where direct measurements are lacking. In terms of modeling requirements, based on those data, we should be able to constrain rates and magnitude of disturbance for vent habitats within a certain range and generate reasonable scenarios of disturbance. We are limited, however, in knowledge of timescales of hydrothermal circulation particularly at slow spreading centers.

The influence of local controls, such as habitat quality and species interactions, are characterized only for a limited suite of species in vents in the eastern and western Pacific and the northern Atlantic, where sustained and repeated access to selected sites has made these measurements possible. Although some of these observations might be generally applicable to other sites (e.g., minimum hydrogen sulfide levels needed to support species that harbor symbionts, maximum temperatures tolerated by different functional or phylogenetic groups, role of foundation species in succession), it seems likely that targeted studies of individual species will be needed to characterize the details of local controls in less well-studied regions, especially those with low disturbance rates and high vent longevity. Similarly, studies of species interactions, which include both direct and indirect evidence for facilitation, competition, and predation, are available only from select sites on the EPR, and mostly during the successional sequence. Competition and predation, in particular, are not well studied for mature communities where continuous, low-level disturbances may alter habitat quality and/or availability. Nevertheless, these observations provide examples of distinct, repeated, successional sequences following disturbance, as well as alternative community development paths triggered by initial colonizers, both of which can be incorporated directly into metacommunity models.

One gap in observations of local control is the influence of habitat quality or changes in local environmental conditions on reproductive output. Fecundity is expected to be high in populations located in high quality patches, or vary over time in response to changes in environmental conditions; however, few reproductive studies at vents have investigated a direct link to habitat. Additionally, while reproductive strategies will affect the temporal patterns in the availability of potential colonists, they are largely unknown (or simply assumed) for most species. However, the range of potential strategies is known and does not differ from those in better known systems in shallow water. Once again, these strategies can be incorporated into metacommunity models to test general hypotheses about the relative importance of reproductive strategies and fecundity on community characteristics, such as resilience, under different disturbance regimes.

Studies of planktonic larval distribution, larval behaviors, and larval duration, coupled with observations and models of oceanic flows, provide insights into regional controls of vent systems. Physical transport processes can be generalized from topographic setting (e.g., the peaks of spreading centers at ridges and back arcs, the valleys of spreading centers, or the flanks of seamounts), each of which has characteristic dynamics. Topographies at particular settings have been mapped by geologists, and models of oceanic flows have been used to develop dispersal kernels and to quantify larval connectivity. While eddy-resolving numerical models are likely to produce fairly accurate dispersal kernels, they may not represent the weak mean abyssal currents correctly. However, on the time scales we are considering (i.e., vent larval pelagic durations of weeks), only strong mean flows will substantially affect dispersal, and those are well represented in models of sufficient resolution.

Larval planktonic durations are known from only a few vent species; they appear to be in the ranges known from related shallow species, although in a few cases, estimated or observed dispersal distances are surprisingly far (implying long duration), especially given the paucity of particulate food in deep waters. Observations reveal evidence for local retention in some species and topographic settings, and long-range dispersal in others, and there is some support for an influence of local populations on larval supply. In total, the field observations of regional controls illustrate that larval connectivity can vary widely among topographic settings, and provide examples of interactions between larval biology, topography of spreading centers, ocean circulation, and vent spacing that are relevant to metacommunity analyses. These examples are tantalizing, and despite the gaps in knowledge of the interaction of topography with ocean circulation at different settings, the use of coupled bio-physical models shows promise.

Classic population genetics approaches have proven useful for identifying barriers to dispersal and boundaries of metapopulations, and new techniques show promise for estimating effective population sizes and rates of directional migration, both of which are relevant to ecological connectivity. Similarly, studies of species distributions on regional and global scales help identify the spatial scale of metacommunities. The inclusion of information about seep metacommunities, which have lower disturbance rates and potentially higher larval connectivity than vents in geologically active regions, broadens the range of values for disturbance and regional influences and offers an opportunity for comparative study.

Field observations not only can inform vent metacommunity analyses, but also reveal patterns that generate hypotheses about how these systems function. For instance, species diversity and distribution patterns vary between the spreading centers located in the eastern Pacific, western Pacific and northern mid-Atlantic regions. Because of differences in spreading rate, and the depths and geological settings of vents, those regions also appear to differ in disturbance, variability in habitat quality, and, potentially, larval connectivity. Thus, the species patterns can be used to motivate specific metacommunity 
analyses, and can be used for comparison with model results.

Given the underlying geological dynamics, we propose that the key questions for metacommunity analysis should focus, at least initially, on how vent ecosystems respond to disturbance linked to these dynamics. Persistence of a metacommunity is of particular interest to ecologists and resource managers evaluating resilience to different magnitudes and frequencies of disturbance. Persistence is assessed with a suite of metrics including time to extinction, proportion of occupied patches, and average time a patch is occupied (Mangel and Tier, 1994; Musick, 1999; Hartley and Kunin, 2003; Frank, 2005). Rates of external larval input from afar that would enable long-term persistence of the metacommunity can be used to evaluate recovery under catastrophic disturbance (great magnitude), whereas the rates of local larval input can be used to evaluate resilience to disturbance of smaller magnitude or smaller spatial extent. Metacommunity approaches can be used to explore relationships between biological processes (time to extinction, larval supply, and successional dynamics) and the magnitude and rate of disturbance.

Species diversity is another main focus of research at hydrothermal vents, and can be evaluated across a range of spatial and temporal scales (e.g., Magurran, 2004). Traditional metrics include alpha (within-site), beta (across-site), and gamma (regional) diversity (Whittaker, 1972), used to describe how richness, evenness, and dominance change over time and space. In the vent context, questions might include: (1) How quickly does diversity at a vent site recover after an eruption? (2) How does spatial heterogeneity of vent dynamics (i.e., where and when vent fields are active) interact with species dispersal ability to affect the rate of succession changes and species' distributions? (3) How do disturbance and connectivity influence the proportion of the regional species pool represented at individual vent fields? These types of analyses may reveal rules of thumb that are consistent across a variety of different geological settings, or alternatively identify relationships that are specific to particular geological, community, or connectivity attributes. Such attributes might include the variability of habitat quality, the influence of individual foundation species, or the directionality of larval transport.

Metacommunity questions can also be specific to an individual vent field (patch), and focus on identifying hotspots of diversity and locations of key ecological significance in systems that are subject to disturbance. The ecological "value" of a vent site depends on the site qualities and species attributes (Ovaskainen and Hanski, 2003), and may be quantified by its contribution to the metacommunity in terms of the capacity for recovery and persistence, the overall occupancy of sites, the recolonization of disturbed sites, or the time to eventual extinction. When ecologists evaluate a site's value, they do so, in part, in terms of its influence on maintaining viable population sizes, minimizing loss of rare species, and maintaining species diversity.

Some of these questions can be addressed theoretically, informed by available data, while others will require new field observations. Given the complexity of the processes and the remoteness of the locations, these data gaps need to be prioritized to focus research efforts. Both the question and the geographic region must be considered when prioritizing. For example, to answer the relatively circumscribed question of how quickly a specific vent community can recover from disturbance, we might focus our field observations on arrival of colonists and the local processes (habitat quality, species interactions) that control community assembly in that specific patch. In contrast, if we wish to address a more synthetic question, such as assigning an ecological value to a specific patch, we would need wider spectrum of information on both regional and local controls (Figure 1). For such an investigation in a well-studied locale (e.g., EPR), where regional characteristics of species composition, and transport processes across the metacommunity, are relatively well known, a focus on local controls would likely maximize new insight. If, instead, the investigation were initiated in a poorly studied region (e.g., a ridge in the Indian Ocean or a largely unexplored arc or back-arc in the western Pacific), we might focus first on characterizing variation in species composition and habitat quality across patches in the region, and in confirming expected patterns of transport and connectivity. Once the regional framework was established, subsequent investigations of local controls could be placed in context. It is important to note that differences between locales in both the regional and local controls need to be considered when attempting to generalize observations from a specific site.

\section{EVALUATING RESILIENCE TO HUMAN DISTURBANCE}

Since their discovery, deep-sea vent communities have been subject to human disturbance. Initially the disturbance was limited to harvesting and manipulation by scientific researchers, but as extraction of vent deposits rich in copper, zinc, silver, and gold becomes economically feasible, mining efforts are being initiated and debate over their regulation is intensifying (Hoagland et al., 2010; Van Dover, 2011; Gobin and da Fonseca, 2014; Mengerink et al., 2014). Mining can result in the destruction of vent communities and alteration of vent habitat, potentially impacting persistence and species diversity by causing further fragmentation in an already fragmented system (Boschen et al., 2016). Metacommunity models are ideal for examining the potential effects of mining because they focus on disturbance, as well as local controls and connectivity. They are useful for informing management decisions because they can be used to explore the effects of mining disturbance at different sites and in different spatial configurations. Characterizing the metacommunity attributes of these deep-sea habitats that contribute to persistence and high regional diversity will also assist with ongoing efforts to identify potential "Ecological or Biologically Significant Marine Areas" that are important for prioritizing management and conservation actions (Convention on Biological Diversity, 2009; Clark et al., 2014).

Discussions of the ecological effects of vent mining often refer to community resilience, which we have defined as the ability of a system to maintain its overall function and structure in 
the face of disturbance (as in Holling, 1973). Resilience is often quantified as the return time for aspects of the system (e.g., species composition, species diversity, functional diversity) to recover to some specific fraction of their initial values. In some cases, an ecosystem may be so drastically disturbed that it passes a critical threshold or tipping point and becomes unlikely to recover to the original state (e.g., Lotze et al., 2011).

The reported return times for vent communities destroyed by eruptions on the EPR and Juan de Fuca to approach preeruption diversity levels are on the order of a decade or less (Tunnicliffe et al., 1997; Shank et al., 1998; Marcus et al., 2009). In the absence of field observations elsewhere, it is tempting to assign these values to regions where mining is expected to occur; however, this would be inappropriate for several reasons. One is that the high disturbance rates at these eastern Pacific sites likely result in species assemblages at individual fields that do not reach equilibrium. In contrast, sites of particular interest for exploitation include large sulfide deposits that may have been active for thousands of years (Tao et al., 2014; German et al., 2016; Cherkashov et al., 2017), thus accumulating species diversities that are at or near equilibrium. Additionally, the close proximity of source communities in the studies on eastern and northeastern Pacific explain, in part, the relative rapid recovery. In most other locations, including areas targeted for mining, the potential for regional larval supply to facilitate recovery may be lower because source populations are farther away. An added complication is that some fauna on active vents are shared with those on inactive vents (Gollner et al., 2013; Boschen et al., 2015), so the latter can, under some circumstances, act as source populations after disturbance events. Consequently, the manner in which community dynamics will change in the event of connectivity disruption in the region is difficult to assess (Boschen et al., 2016). Furthermore, the disturbances from mining activities differs from natural disturbance in that they leave behind sediment and rubble (Steiner, 2009), rather than pillow lavas or sheet flows (Chadwick et al., 2001). Mining activities are expected to result in significant changes in the quality and availability of patches, which in turn will affect community recovery by altering settlement cues, rates of colonization, and post-settlement survival, and may impede recovery by forcing the ecosystem beyond its tipping point. At the very least, biodiversity loss is inevitable at a vent field that is the focus of a mining operation (Van Dover et al., 2017).

Under the UN Law of the Sea (UNCLOS), it is the International Seabed Authority (ISA) that authorizes exploration and exploitation claims for mineral resources in international waters and has the general obligation to protect the marine environment from harmful effects of mining. The first international seabed massive sulfide (SMS) exploration claims were granted in 2011 and current claims in international waters are located on the Mid-Atlantic Ridge and both Southwest and Central Indian Ridges. Additionally, there are many west Pacific island nations with SMS resources within their exclusive economic zones (EEZs) that have issued exploration claims to independent companies. Countries that are party to UNCLOS also must develop mining regulations for their EEZs at least as stringent as those that developed by the ISA.
Several principles have guided the development of these regulations including the common heritage of mankind, the precautionary approach, best environmental practices, and ecosystem-based management (International Seabed Authority., 2016). Application of ecosystem-based approaches can occur through overarching environmental objectives that are addressed by (i) strategic and regional environmental planning at a broad scale, and (ii) at the claim level with environmental management plans including environmental impact assessments that address baseline data generation, the mitigation hierarchy, and preand post-impact monitoring. Data on both metapopulation connectivity and metacommunity interactions can inform many aspects of this process and can provide an important framework for planning and assessment. In particular, the regional designations of Areas of Particular Environmental Interest (APEIs) and the designation of no-impact Protected Reference Zones (PRZs) within SMS claims, should be based on an understanding of uniqueness, endemicity and isolation, as well as recovery potential and resilience for different vent communities and taxa. EIA templates need to incorporate the requisite metacommunity information to allow decision making and no-mining designations.

Assessment of cumulative impacts and recovery from multiple types of mining impacts, multiple mining actions and multiple sectors such as fishing and marine transportation is another area where metacommunity attributes are critical to decision making. In addition, the legal thresholds imposed within UNCLOS by the concepts of harmful effects (to be avoided) and serious harm (to stop mining or not mine; Levin et al., 2016b) are now being defined: one proposal is that they be informed by biogeographic evaluations of (vent) assemblages as metacommunities, where serious harm becomes a level of destruction that results in functional extinction of taxa or effective loss of habitat type within a metacommunity framework.

To manage deep-sea mining in a way that preserves the ecological value of hydrothermal vent communities, a method is needed to assess how mining can influence species persistence, community resilience, and regional diversity. This is a challenging task, given the limited availability of observations on local controls and larval connectivity, particularly from the less studied regions of the seafloor. Nevertheless, metacommunity models offer a critical first step toward this goal, and represent the best available approach to understanding regional effects.

\section{CONCLUSIONS}

Two of the main objectives of this paper are to inform deepsea ecologists about the value of studying vent communities in a metacommunity framework, and to inform metacommunity modelers about the unique attributes of vent systems. We show that a full understanding of diversity and dynamics of vent ecosystems can be obtained only through combined investigation of both local and regional processes. Vent metacommunities are particularly intriguing from a modeling perspective because the distribution and dynamics of patches are controlled by 
fundamental earth systems processes of plate tectonics and magma supply.

Another goal is to identify gaps in field observations that presently impede metacommunity investigation. Notable gaps include information on reproductive output and larval planktonic duration, which is limited to only a few species, and often inferred from morphology or by analogy with related shallow species. In addition, although data on local controls (e.g., habitat requirements and species interactions) are available from well-studied locations in the Pacific and Atlantic, they are missing from less-accessible areas such as the Indian Ocean or high latitude seas where exploration is limited. In contrast, observations of some other key processes are well characterized. In particular, the global distribution of vents is increasingly well characterized, and aspects of their dynamics are predictable from their tectonic and magmatic setting. Furthermore, physical transport in each of three typical topographic settings (axial valley, ridge, and seamount) is well described with a combination of observations and models. The spatial extent of metapopulations in several regions is well constrained by population genetic studies.

These field observations inform investigations of several key questions in vent ecology that can be solved with metacommunity models: (1) What is the influence of the magnitude and rate of disturbance on ecological attributes such as time to extinction or resilience in a metacommunity? (2) What interactions between local and regional processes control species diversity? And (3) Which communities are 'hot spots' of key ecological significance? There is value in addressing these questions in general terms, independent of specific geographic region, as they increase our understanding of the underlying processes controlling vent metacommunities. An ability, however, to address problems specific to a region is needed to investigate the resilience of individual vent fields to disturbance. We suggest that evaluating resilience is possible in accessible regions, where local controls on species' habitat requirements and interactions are known, but not yet feasible

\section{REFERENCES}

Abbott, K. C. (2011). A dispersal-induced paradox: synchrony and stability in stochastic metapopulations. Ecol. Lett. 14, 1158-1169. doi: 10.1111/j.1461-0248.2011.01670.x

Adams, D. K., Arellano, S. M., and Govenar, B. (2012). Larval dispersal: vent life in the water column. Oceanography 25, 256-268. doi: 10.5670/oceanog.2012.24

Adams, D. K., McGillicuddy, D. J., Zamudio, L., Thurnherr, A. M., Liang, X., Rouxel, O., et al. (2011). Surface-generated mesoscale eddies transport deep-sea products from hydrothermal vents. Science 332, 580-583. doi: 10.1126/science.1201066

Adams, D. K., and Mullineaux, L. S. (2008). Supply of gastropod larvae to hydrothermal vents reflects transport from local larval sources. Limnol. Oceanogr. 53, 1945 - 1955. doi: 10.4319/lo.2008.53.5.1945

Amante, C., and Eakins, B. W. (2009). "ETOPO1 1 arc-minute global relief model: procedures, data sources and analysis," in NOAA Technical Memorandum NESDIS NGDC-24 (Boulder, CO: National Geophysical Data Center, NOAA).

Bachraty, C., Legendre, P., and Desbruyeres, D. (2009). Biogeographic relationships among deep-sea hydrothermal vent faunas at global scale. Deep Sea Res. I Oceanogr. Res. Pap. 56, 1371-1378. doi: 10.1016/j.dsr.2009.01.009 in remote locales where that information is missing. Most of the vent sites under exploration for mining do not yet have the requisite species-level observations to support estimates of resilience.

\section{AUTHOR CONTRIBUTIONS}

LM and AM were the intellectual leads on the paper, wrote individual sections and edited drafts of the manuscript. SB wrote a section and edited drafts. MB co-wrote a section. SG co-wrote a section and edited drafts. BG co-wrote a section and edited drafts. $\mathrm{SH}$ co-wrote a section and edited drafts. JK co-wrote a section. LL co-wrote sections and edited drafts. SM co-wrote a section. $\mathrm{MN}$ wrote a section and edited drafts. AT co-wrote a section and edited drafts. VT wrote a section and edited drafts. HW co-wrote a section. Y-JW co-wrote a section.

\section{FUNDING}

LM was supported by NSF OCE 1356738 and DEB 1558904. SB was supported by the NSF DEB 1558904 and the Investment in Science Fund at Woods Hole Oceanographic Institution. MB was supported by the Austrian Science Fund grants P20190-B17 and P16774-B03. LL was supported by NSF OCE 1634172 and the JM Kaplan Fund. MN was supported by NSF DEB 1558904. Y-JW was supported by a Korean Institute of Ocean Science and Technology (KIOST) grant PM60210.

\section{ACKNOWLEDGMENTS}

This manuscript is the product of the InterRidge Working Group on Ecological Connectivity and Resilience, chaired by AM and LM. Colleagues E. Baker, W. Chadwick, Jr., D. Fornari, C. German, A. Phillips, D. Smith, and M.K. Tivey provided comments on the manuscript. BG held a NSERC Visiting Fellowship to a Government Lab. VT was supported by the Canada Research Chair program.

Baker, E. T., Embley, R. W., Walker, S. L., Resing, J. A., Lupton, J. E., Nakamura, K., et al. (2008). Hydrothermal activity and volcano distribution along the Mariana arc. J. Geophys. Res. Solid Earth 113:B08S09. doi: 10.1029/2007JB005423

Baker, E. T., and Massoth, G. J. (1987). Characteristics of hydrothermal plumes from two vent fields on the Juan de Fuca Ridge, northeast Pacific Ocean. Earth Planet. Sci. Lett. 85, 59-73. doi: 10.1016/0012-821X(87)90021-5

Baker, E. T., Resing, J. A., Haymon, R. M., Tunnicliffe, V., Lavelle, J. W., Martinez, F., et al. (2016). How many vent fields? New estimates of vent field populations on ocean ridges from precise mapping of hydrothermal discharge locations. Earth Planet. Sci. Lett. 449, 186-196. doi: 10.1016/j.epsl.2016.05.031

Bates, A. E., Tunnicliffe, V., and Lee, R. W. (2005). Role of thermal conditions in habitat selection by hydrothermal vent gastropods. Mar. Ecol. Prog. Ser. 305, 1-15. doi: 10.3354/meps305001

Beaulieu, S. E. (2015). InterRidge Global database of Active Submarine Hydrothermal Vent Fields. Prepared for InterRidge, Version 3.3, kml file produced 16 September 2015. Available online at: http://vents-data.interridge. org

Beaulieu, S. E., Baker, E. T., and German, C. R. (2015). Where are the undiscovered hydrothermal vents on oceanic spreading ridges? Deep Sea Res. II Top. Stud. Oceanogr. 121, 202-212. doi: 10.1016/j.dsr2.2015.05.001 
Beaulieu, S. E., Baker, E. T., German, C. R., and Maffei, A. (2013). An authoritative global database for active submarine hydrothermal vent fields. Geochem. Geophys. Geosys. 14, 4892-4905. doi: 10.1002/2013GC004998

Beedessee, G., Watanabe, H., Ogura, T., Nemoto, S., Yahagi, T., Nakagawa, S., et al. (2013). High connectivity of animal populations in deep-sea hydrothermal vent fields in the Central Indian Ridge relevant to its geological setting. PLOS ONE 8:e81570. doi: 10.1371/journal.pone.0081570

Beerli, P., and Felsenstein, J. (2001). Maximum likelihood estimation of a migration matrix and effective population sizes in $\mathrm{n}$ subpopulations by using a coalescent approach. Proc. Natl. Acad. Sci. U.S.A. 98, 4563-4568. doi: $10.1073 /$ pnas. 081068098

Beerli, P., and Palczewski, M. (2010). Unified framework to evaluate panmixia and migration direction among multiple sampling locations. Genetics 185, 313-326. doi: 10.1534/genetics.109.112532

Begon, M., Harper, J. L., and Townsend, C. R. (1990). Ecology: Individuals, Populations, and Communities. Oxford: Blackwell.

Bell, J. B., Aquilina, A., Woulds, C., Glover, A. G., Little, C. T., Reid, W. D., et al. (2016). Geochemistry, faunal composition and trophic structure in reducing sediments on the southwest South Georgia margin. R. Soc. Open Sci. 3:160284. doi: 10.1098/rsos.160284

Berkley, H. A., Kendall, B. E., Mitarai, S., and Siegel, D. A. (2010). Turbulent dispersal promotes species coexistence. Ecol. Lett. 13, 360-371. doi: 10.1111/j.1461-0248.2009.01427.x

Bird, P. (2003). An updated digital model of plate boundaries. Geochem. Geophys. Geosyst. 4:1027. doi: 10.1029/2001GC000252

Bloch, C. P., Higgins, C. L., and Willig, M. R. (2007). Effects of large-scale disturbance on metacommunity structure of terrestrial gastropods: temporal trands in nestedness. Oikos 116, 395-406. doi: 10.1111/j.0030-1299.2007.15391.x

Boetius, A., Ravenschlag, K., Schubert, C. J., Rickert, D., Widdel, F., Gieseke, A., et al. (2000). A marine microbial consortium apparently mediating anaerobic oxidation of methane. Nature 407, 623-626. doi: 10.1038/35036572

Bohrer, G., Nathan, R., and Volis, S. (2005). Effects of long-distance dispersal for metapopulation survival and genetic structure at ecological time and spatial scales. J. Ecol. 93, 1029-1040. doi: 10.1111/j.1365-2745.2005.01048.x

Boschen, R. E., Rowden, A. A., Clark, M. R., Barton, S. J., Pallentin, A., and Gardner, J. P. A. (2015). Megabenthic assemblage structure on three New Zealand seamounts: implications for seafloor massive sulfide mining. Mar. Ecol. Prog. Ser. 523, 1-14. doi: 10.3354/meps11239

Boschen, R. E., Rowden, A. A., Clark, M. R., Pallentin, A., and Gardner, J. P. (2016). Seafloor massive sulfide deposits support unique megafaunal assemblages: implications for seabed mining and conservation. Mar. Environ. Res. 115, 78-88. doi: 10.1016/j.marenvres.2016.02.005

Breusing, C., Biastoch, A., Drews, A., Metaxas, A., Jollivet, D., Vrijenhoek, R. C., et al. (2016). Biophysical and population genetic models predict the presence of "phantom" stepping stones connecting Mid-Atlantic Ridge vent ecosystems. Curr. Biol. 26, 2257-2267. doi: 10.1016/j.cub.2016.06.062

Breusing, C., Johnson, S. B., Tunnicliffe, V., and Vrijenhoek, R. C. (2015). Population structure and connectivity in Indo-Pacific deep-sea mussels of the Bathymodiolus septemdierum complex. Conserv. Genet. 16, 1415-1430. doi: 10.1007/s10592-015-0750-0

Briggs, C. J., and Hoopes, M. F. (2004). Stabilizing effects in spatial parasitoidhost and predator-prey models: a review. Theor. Popul. Biol. 65, 299-315. doi: 10.1016/j.tpb.2003.11.001

Broquet, T., and Petit, E. J. (2009). Molecular estimation of dispersal for ecology and population genetics. Ann. Rev. Ecol. Evol. Syst. 40, 193-216. doi: 10.1146/annurev.ecolsys.110308.120324

Brown, B. L., and Swan, C. M. (2010). Dendritic network structure constrains metacommunity properties in riverine ecosystems. J. Anim. Ecol. 79, 571-580. doi: 10.1111/j.1365-2656.2010.01668.x

Butterfield, D. A., Nakamura, K., Takano, B., Lilley, M. D., Lupton, J. E., Resing, J. A., et al. (2011). High $\mathrm{SO}_{2}$ flux, sulfur accumulation, and gas fractionation at an erupting submarine volcano. Geology 39, 803-806. doi: 10.1130/G31901.1

Cabral, J. S., Weigelt, P., Kissling, W. D., and Kreft, H. (2014). Biogeographic, climatic and spatial drivers differentially affect alpha-, beta- and gammadiversities on oceanic archipelagos. Proc. R. Soc. B Biol. Sci. 281:20133246. doi: 10.1098/rspb.2013.3246
Campbell, R. E., Winterbourn, M. J., Cochrane, T. A., and McIntosh, A. R. (2015). Flow-related disturbance creates a gradient of metacommunity types within stream networks. Landsc. Ecol. 30, 67-680. doi: 10.1007/s10980-015-0164-x

Cannon, G. A., and Pashinski, D. J. (1997). Variations in mean currents affecting hydrothermal plumes on the Juan de Fuca Ridge. J. Geophys. Res. 102, 24965-24976. doi: 10.1029/97JC01910

Cannon, G. A., Pashinski, D. J., and Lemon, M. R. (1991). Middepth flow near hydrothermal venting sites on the southern Juan de Fuca ridge. J. Geophys. Res. 96, 12815-12831. doi: 10.1029/91JC01023

Caswell, H., and Cohen, J. E. (eds.). (1993). Local and Regional Regulation of Species-Area Relations: A Patch-Occupancy Model. Chicago: University of Chicago Press.

Caswell, H., and Etter, R. J. (1993). "Ecological interactions in patchy environments: from patch-occupancy model to cellular automata," in Patch Dynamics, ed S. A. Levin (Heidelberg: Springer Verlag), 93-109.

Chadwick, W. W., Scheirer, D. S., Embley, R. W., and Johnson, H. P. (2001). Highresolution bathymetric surveys using scanning sonars: Lava flow morphology, hydrothermal vents, and geologic structure at recent eruption sites on the Juan de Fuca Ridge. J. Geophys. Res. 106, 16075-16099. doi: 10.1029/2001JB000297

Chen, C., Copley, J. T., Linse, K., and Rogers, A. D. (2015). Low connectivity between 'scaly-foot gastropod' (Mollusca: Peltospiridae) populations at hydrothermal vents on the Southwest Indian Ridge and the Central Indian Ridge. Organ. Divers. Evol. 15, 663-670. doi: 10.1007/s13127-015-0224-8

Cherkashov, G., Kuznetsov, V., Kuksa, K., Tabuns, E., Maksimov, F., and Bel'tenev, V. (2017). Sulfide geochronology along the Northern Equatorial Mid-Atlantic Ridge. Ore Geol. Rev. 87, 147-154. doi: 10.1016/j.oregeorev.2016.10.015

Clark, M. R., Rowden, A. A., Schlacher, T. A., Guinotte, J., Dunstan, P. K., Williams, A., et al. (2014). Identifying Ecologically or Biologically Significant Areas (EBSA): a systematic method and its application to seamounts in the South Pacific Ocean. Ocean Coast. Manag. 91, 65-79. doi: 10.1016/j.ocecoaman.2014.01.016

Colaço, A., Dehairs, F., and Desbruyères, D. (2002). Nutritional relations of deepsea hydrothermal fields at the Mid-Atlantic Ridge: a stable isotope approach. Deep Sea Res. 49, 395-412. doi: 10.1016/S0967-0637(01)00060-7

Colwell, R. K., Rahbek, C., and Gotelli, N. J. (2004). The mid-domain effect and species richness patterns: what have we learned so far? Am. Nat. 163, E1-E23. doi: $10.1086 / 382056$

Connell, J. H., and Slatyer, R. O. (1977). Mechanisms of succession in natural communities and their role in community stability and organization. Am. Nat. 111, 1119-1144. doi: 10.1086/283241

Convention on Biological Diversity (2009). Azores Scientific Criteria and Guidance for Identifying Ecologically or Biologically Significant Marine Areas and Designing Representative Networks of Marine Protected Areas in Open Ocean Waters and Deep Sea Habitats. Montreal, QC: Secretary General, United Nations.

Cordes, E. E., Becker, E. L., Hourdez, S., and Fisher, C. R. (2010). Influence of foundation species, depth, and location on diversity and community composition at Gulf of Mexico lower-slope cold seeps. Deep Sea Res. II Top. Stud. Oceanogr. 57, 1870-1881. doi: 10.1016/j.dsr2.2010.05.010

Cordes, E. E., Bergquist, D. C., and Fisher, C. R. (2009). Macroecology of gulf of Mexico cold seeps. Ann. Rev. Mar. Sci. 1, 143-168. doi: 10.1146/annurev.marine.010908.163912

Cottenie, K., Michels, E., Nuytten, N., and DeMeester, L. (2003). Zooplankton metacommunity structure: regional vs. local processes in highly interconnected ponds. Ecology 84, 991-1000. doi: 10.1890/00129658(2003)084[0991:ZMSRVL]2.0.CO;2

Coykendall, D. K., Johnson, S. B., Karl, S. A., Lutz, R. A., and Vrijenhoek, R. C. (2011). Genetic diversity and demographic instability in Riftia pachyptila tubeworms from eastern Pacific hydrothermal vents. BMC Evol. Biol. 11:96. doi: 10.1186/1471-2148-11-96

Cuvelier, D., Sarrazin, J., Colaco, A., Copley, J., Desbruyeres, D., Glover, A. G., et al. (2009). Distribution and spatial variation of hydrothermal faunal assemblages at Lucky Strike (Mid-Atlantic Ridge) revealed by high-resolution video image analysis. Deep Sea Res. I Oceanogr. Res. Pap. 56, 2026-2040. doi: 10.1016/j.dsr.2009.06.006

Cuvelier, D., Sarrazin, J., Colaco, A., Copley, J. T., Glover, A. G., Tyler, P. A., et al. (2011). Community dynamics over 14 years at the Eiffel Tower 
hydrothermal edifice on the Mid-Atlantic Ridge. Limnol. Oceanogr. 56, 1624-1640. doi: 10.4319/lo.2011.56.5.1624

Daigle, R. M., Chasse, J., and Metaxas, A. (2016). The relative effect of behaviour in larval dispersal in a low energy embayment. Prog. Oceanogr. 144, 93-117. doi: 10.1016/j.pocean.2016.04.001

de Ronde, C. E. J., Baker, E. T., Massoth, G. J., Lupton, J. E., Wright, I. C., Sparks, R. J., et al. (2007). Submarine hydrothermal activity along the mid-Kermadec Arc, New Zealand: Large-scale effects on venting. Geochemistry Geophysics Geosystems 8:Q07007. doi: 10.1029/2006GC001495

Desbruyères, D., Almeida, A., Biscoito, M., Comtet, T., Khripounoff, A., Le Bris, N., et al. (2000). A review of the distribution of hydrothermal vent communities along the northern Mid-Atlantic Ridge: dispersal vs. environmental controls. Hydrobiologia 440, 201-216. doi: 10.1023/A:1004175211848

Desbruyères, D., Biscoito, M., Caprais, J. C., Colaco, A., Comtet, T., Crassous, P., et al. (2001). Variations in deep-sea hydrothermal vent communities on the Mid-Atlantic Ridge near the Azores plateau. Deep Sea Res. I Oceanogr. Res. Pap. 48, 1325-1346. doi: 10.1016/S0967-0637(00)00083-2

Desbruyères, D., Segonzac, M., and Bright, M. (2006). Handbook of Deep-Sea Hydrothermal Vent Fauna. Linz: Landesmuseen.

Dittel, A. I., Perovich, G., and Epifanio, C. E. (2008). Biology of the vent crab Bythograea thermydron: a brief review. J. Shellfish Res. 27, 63-77. doi: 10.2983/ 0730-8000(2008)27[63:BOTVCB]2.0.CO;2

Dziak, R. P., Bohnenstiehl, D. R., and Smith, D. K. (2012). Hydroacoustic monitoring of oceanic spreading centers, past, present, and future. Oceanography 25, 116-127. doi: 10.5670/oceanog.2012.10

Embley, R. W., Chadwick, W. W., Baker, E. T., Butterfield, D. A., Resing, J. A., de Ronde, C. E., et al. (2006). Long-term eruptive activity at a submarine arc volcano. Nature 441, 494-497. doi: 10.1038/nature04762

Embley, R. W., Merle, S. G., Baker, E. T., Rubin, K. H., Lupton, J. E., Resing, J. A., et al. (2014). Eruptive modes and hiatus of volcanism at West Mata seamount, NE Lau basin: 1996-2012. Geochem. Geophys. Geosyst. 15, 4093-4115. doi: 10.1002/2014GC005387

Eriksen, C. C. (1991). Observations of amplified flows atop a large seamount. J. Geophys. Res. Oceans 96, 15227-15236. doi: 10.1029/91JC 01176

Escartín, J., Smith, D. K., Cann, J., Schouten, H., Langmuir, C. H., and Escrig, S. (2008). Central role of detachment faults in accretion of slow-spreading oceanic lithosphere. Nature 455, 790-795. doi: 10.1038/nature07333

Faubet, P., and Gaggiotti, O. E. (2008). A new Bayesian method to identify the environmental factors that influence recent migration. Genetics 178, 1491-1504. doi: 10.1534/genetics.107.082560

Faubet, P., Waples, R. S., and Gaggiotti, O. E. (2007). Evaluating the performance of a multilocus Bayesian method for the estimation of migration rates. Mol. Ecol. 16, 1149-1166. doi: 10.1111/j.1365-294X.2007.03218.x

Fisher, C. R., Childress, J. J., Brooks, J. M., and Macko, S. A. (1994). Nutritional interactions in Galapagos Rift hydrothermal vent communities: inferences from stable carbon and nitrogen isotope analyses. Mar. Ecol. Prog. Ser. 103, 45-55. doi: $10.3354 /$ meps 103045

Fornari, D. J., and Embley, R. W. (1995). "Tectonic and volcanic controls on hydrothermal processes at the mid-ocean ridge: an overview based on nearbottom and submersible studies," in Seafloor Hydrothermal Systems: Physical, Chemical, Biological, and Geological Interactions, eds S. E. Humphris, R. A. Zierenberg, L. S. Mullineaux, and R. E. Thomson (Washington, DC: American Geophysical Union), 1-46.

Fornari, D. J., Von Damm, K. L., Bryce, J. G., Cowen, J. P., Ferrini, V., Fundis, A., et al. (2012). The East Pacific Rise between $9^{\circ} \mathrm{N}$ and $10^{\circ} \mathrm{N}$ : twenty-five years of integrated, multidisciplinary oceanic spreading center studies. Oceanography 25, 18-43. doi: 10.5670/oceanog.2012.02

Frank, K. (2005). Metapopulation persistence in heterogeneous landscapes: lessons about the effect of stochasticity. Am. Nat. 165, 374-388. doi: 10.1086/428293

Gamo, T., Ishibashi, J., Tsunogai, U., Okamura, K., and Chiba, H. (2006). “Unique geochemistry of submarine hydrothermal fluids from arc-backarc settings of the western Pacific," in Back-Arc Spreading Systems: Geological, Biological, Chemical, and Physical Interactions, eds D. M. Christie, C. R. Fisher, S. M. Lee, and S. Givens (Washington, DC: American Geophysical Union), 147-162.

Gaudron, S. M., Pradillon, F., Pailleret, M., Duperron, S., Le Bris, N., and Gaill, F. (2010). Colonization of organic substrates deployed in deep-sea reducing habitats by symbiotic species and associated fauna. Mar. Environ. Res. 70, 1-12. doi: 10.1016/j.marenvres.2010.02.002

Gebruk, A., Fabri, M. C., Briand, P., and Desbruyères, D. (2010). Community dynamics over a decadal scale at Logatchev, $14^{\circ} 45^{\prime} \mathrm{N}$, Mid-Atlantic Ridge. Cah. Biol. Mar. 51, 383-388.

German, C. R., Baker, E. T., and Klinkhammer, G. (1995). Regional setting of hydrothermal activity. Geol. Soc. Lond. Spec. Publ. 87, 3-15. doi: 10.1144/GSL.SP.1995.087.01.02

German, C. R., Petersen, S., and Hannington, M. D. (2016). Hydrothermal exploration of mid-ocean ridges: where might the largest sulfide deposits be forming? Chem. Geol. 420, 114-126. doi: 10.1016/j.chemgeo.2015.11.006

German, C. R., and Seyfried, W. E. (2013). "Hydrothermal processes," in Treatise on Geochemistry, 2nd Edn., eds K. Turekian and H. Holland (Amsterdam: Elsevier Inc.), 191-233.

Gilpin, M. E., and Hanski, I. A. (1991). Metapopulation Dynamics: Empirical and Theoretical Investigations. London: Academic Press.

Gobin, C., and da Fonseca, G. A. (2014). Deep-sea protection: coordinate efforts. Science 344, 1352-1352. doi: 10.1126/science.344.6190.1352

Goffredi, S. K., Johnson, S., Tunnicliffe, V., Caress, D., Clague, D., Escobar, E., et al. (2017). Hydrothermal vent fields discovered in the southern Gulf of California clarify role of habitat in augmenting regional diversity. Proc. Biol. Sci. 284:20170817. doi: 10.1098/rspb.2017.0817

Gollner, S., Govenar, B., Arbizu, P. M., Mills, S., Le Bris, N., Weinbauer, M., et al. (2015). Differences in recovery between deep-sea hydrothermal vent and ventproximate communities after a volcanic eruption. Deep Sea Res. I Oceanogr. Res. Pap. 106, 167-182. doi: 10.1016/j.dsr.2015.10.008

Gollner, S., Kaiser, S., Menzel, L., Jones, D. O. B., Brown, A., Mestre, N. C., et al. (2017). Resilience of benthic deep-sea fauna to mining activities. Mar. Environ. Res. 129, 76-101. doi: 10.1016/j.marenvres.2017.04.010

Gollner, S., Miljutina, M., and Bright, M. (2013). Nematode succession at deep-sea hydrothermal vents after a recent volcanic eruption with the description of two dominant species. Organ. Divers. Evol. 13, 349-371. doi: 10.1007/s13127-012-0122-2

Gollner, S., Riemer, B., Arbizu, P. M., Le Bris, N., and Bright, M. (2010). Diversity of meiofauna from the $9^{\circ} 50^{\prime} \mathrm{N}$ East Pacific Rise across a gradient of hydrothermal fluid emissions. PLoS ONE 5:e12321. doi: 10.1371/journal.pone.0012321

Gollner, S., Stuckas, H., Kihara, T. C., Laurent, S., Kodami, S., and Arbizu, P. (2016). Mitochondrial DNA analyses indicate high diversity, expansive population growth and high genetic connectivity of vent copepods (Dirivultidae) across different oceans. PLoS ONE 11:e0163776. doi: 10.1371/journal.pone.0163776

Govenar, B. (2010). Shaping vent and seep communities: habitat provision and modification by foundation species. Top. Geobiol. 33, 403-432. doi: 10.1007/978-90-481-9572-5_13

Govenar, B., and Fisher, C. R. (2007). Experimental evidence of habitat provision by aggregations of Riftia pachyptila at hydrothermal vents on the East Pacific Rise. Mar. Ecol. Evol. Perspect. 28, 3-14. doi: 10.1111/j.1439-0485.2007. 00148.x

Grupe, B. M. (2014). Implications of Environmental Heterogeneity for Community Structure, Colonization, and Trophic Dynamics at Eastern Pacific Methane Seeps. Ph.D., University of California San Diego.

Guichard, F., Levin, S. A., Hastings, A., and Siegel, D. (2004). Toward a dynamic metacommunity approach to marine reserve theory. Bioscience 54, 1003-1011. doi: 10.1641/0006-3568(2004)054[1003:TADMAT]2.0.CO;2

Hanski, I. A., and Gilpin, M. E. (1991). Metapopulation dynamics: brief history and conceptual domain. Biol. J. Linnean Soc. 42, 3-16. doi: 10.1111/j.1095-8312.1991.tb00548.x

Hanski, I. A., and Simberloff, D. (1997). “The metapopulation approach, its history, conceptual domain, and application to conservation," in Metapopulation Biology: Ecology, Genetics, and Evolution, eds I. A. Hanski and M. E. Gilpin (San Diego, CA: Academic Press), 5-26.

Hartley, S., and Kunin, W. E. (2003). Scale dependency of rarity, extinction risk, and conservation priority. Conserv. Biol. 17, 1559-1570. doi: 10.1111/j.1523-1739.2003.00015.x

Haymon, R. M., McDonald, K. C., Benjamin, S. B., and Ehrhardt, C. J. (2005). Manifestations of hydrothermal discharge from young abyssal hills on the fastspreading East Pacific Rise flank. Geology 33, 153-156. doi: 10.1130/G21058.1 
Helfrich, K. R., Joyce, T. M., Cannon, G. A., Harrington, S. A., and Pashinski, D. J. (1998). Mean hydrographic and velocity sections near Pipe Organ vent at Juan de Fuca Ridge. Geophys. Res. Lett. 25, 1737-1740. doi: 10.1029/98GL01308

Hellberg, M. E. (2009). Gene flow and isolation among populations of marine animals. Annu. Rev. Ecol. Evol. Syst. 40, 291-310. doi: 10.1146/annurev.ecolsys.110308.120223

Herrera, S., Reyes-Herrera, P. H., and Shank, T. M. (2015a). Predicting RADseq marker numbers across the eukaryotic tree of life. Genome Biol. Evol. 7, 3207-3225. doi: 10.1093/gbe/evv210

Herrera, S., Watanabe, H., and Shank, T. M. (2015b). Evolutionary and biogeographical patterns of barnacles from deep-sea hydrothermal vents. Mol. Ecol. 24, 673-689. doi: 10.1111/mec.13054

Herring, P. J., and Dixon, D. R. (1998). Extensive deep-sea dispersal of postlarval shrimp from a hydrothermal vent. Deep Sea Res. 45(Pt 1), 2105-2118. doi: 10.1016/S0967-0637(98)00050-8

Hessler, R. R., Smithey, W. M., and Keller, C. H. (1985). Spatial and temporal variation of giant clams, tubeworms and mussels at deep-sea hydrothermal vents. Bull. Biol. Soc. Wash. 6, 411-428.

Hilario, A., Metaxas, A., Gaudron, S. M., Howell, K. L., Mercier, A., Mestre, N., et al. (2015). Estimating dispersal distance in the deep sea: challenges and applications to marine reserves. Front. Mar. Sci. 2:6. doi: $10.3389 /$ fmars.2015.00006

Hoagland, P., Beaulieu, S., Tivey, M. A., Eggert, R. G., German, C., Glowka, L., et al. (2010). Deep-sea mining of seafloor massive sulfides. Mar. Policy 34, 728-732. doi: 10.1016/j.marpol.2009.12.001

Holling, C. S. (1973). Resilience and stability of ecological systems. Annu. Rev. Ecol. Syst. 4, 1-23. doi: 10.1146/annurev.es.04.110173.000245

Hornbach, M. J., Ruppel, C., and Van Dover, C. L. (2007). Three-dimensional structure of fluid conduits sustaining an active deep marine cold seep. Geophys. Res. Lett. 34:L05601. doi: 10.1029/2006GL028859

International Seabed Authority. (2016). Working Draft Regulations and Standard Contract Terms on Exploitation for Mineral Resources in the Area. Kingston: International Seabed Authority.

Jackson, P. R., Ledwell, J. R., and Thurnherr, A. M. (2010). Dispersion of a tracer on the East Pacific Rise $\left(9^{\circ} \mathrm{N}\right.$ to $\left.10^{\circ} \mathrm{N}\right)$, including the influence of hydrothermal plumes. Deep Sea Res. I Oceanogr. Res. Pap 57, 37-52. doi: 10.1016/j.dsr.2009.10.011

Jamieson, J. W., Clague, D. A., and Hannington, M. D. (2014). Hydrothermal sulfide accumulation along the Endeavour Segment, Juan de Fuca Ridge. Earth Planet. Sci. Lett. 395, 136-148. doi: 10.1016/j.epsl.2014.03.035

Jamieson, J. W., Hannington, M. D., Clague, D. A., Kelley, D. S., Delaney, J. R., Holden, J. F., et al. (2013). Sulfide geochronology along the Endeavour Segment of the Juan de Fuca Ridge. Geochem. Geophys. Geosyst. 14, 2084-2099. doi: 10.1002 /ggge.20133

Jang, S. J., Park, E., Lee, W. K., Johnson, S. B., Vrijenhoek, R. C., and Won, Y. J. (2016). Population subdivision of hydrothermal vent polychaete Alvinella pompejana across equatorial and Easter Microplate boundaries. BMC Evol. Biol. 16:235. doi: 10.1186/s12862-016-0807-9

Johnson, K. S., Childress, J. J., Hessler, R. R., Sakamoto-Arnold, C. M., and Beehler, C. L. (1988). Chemical and biological interactions in the Rose Garden hydrothermal vent field, Galapagos spreading center. Deep Sea Res. 35, 1723-1744. doi: 10.1016/0198-0149(88)90046-5

Johnson, S. B., Waren, A., Tunnicliffe, V., Van Dover, C. L., Wheat, G. C., Schultz, T. F., et al. (2014). Molecular taxonomy and naming of five cryptic species of Alviniconcha snaila (Gastropoda: Abyssochrysoidea) from hydrothermal vents. Syst. Biodiv. 13, 278-295. doi: 10.1080/14772000.2014.970673

Johnson, S. B., Young, C. R., Jones, W. J., Warén, A., and Vrijenhoek, R. C. (2006). Migration, isolation, and speciation of hydrothermal vent limpets (Gastropoda; Lepetodrilidae) across the Blanco Transform Fault. Biol. Bull. 210, 140-157. doi: $10.2307 / 4134603$

Jollivet, D., Chevaldonne, P., and Planque, B. (1999). Hydrothermalvent alvinellid polychaete dispersal in the eastern Pacific. 2. A metapopulation model based on habitat shifts. Evolution 53, 1128-1142. doi: 10.1111/j.1558-5646.1999.tb04527.x

Juniper, S. K., and Tunnicliffe, V. (1997). Crustal accretion and the hot vent ecosystem. Philos. Trans. R. Soc. Lond. A 355, 459-474. doi: 10.1098/rsta.1997.0017
Juniper, S. K., Tunnicliffe, V., and Desbruyères, D. (1990). "Regional-scale features of northeast Pacific, East Pacific Rise, and Gulf of Aden vent communities," in Gorda Ridge, ed G. R. McMurray (New York, NY: Springer), 265-278.

Kaneko, K. (1993). Theory and Application of Coupled Map Lattices. Chichester: Wiley.

Kelley, D. S., Karson, J. A., Früh-Green, G. L., Yoerger, D. R., Shank, T. M., Butterfield, D. A., et al. (2005). A serpentinite-hosted ecosystem: the Lost City hydrothermal field. Science 307, 1428-1434. doi: 10.1126/science.1102556

Kelly, N. E., and Metaxas, A. (2007). Influence of habitat on the reproductive biology of the deep-sea hydrothermal vent limpet Lepetodrilus fucensis (Vetigastropoda: Mollusca) from the Northeast Pacific. Mar. Biol. 151, 649-662. doi: 10.1007/s00227-006-0505-z

Kelly, N., and Metaxas, A. (2008). Diversity of invertebrate colonists on simple and complex substrates at hydrothermal vents on the Juan de Fuca Ridge. Aquat. Biol. 3, 271-281. doi: 10.3354/ab00085

Kelly, N., and Metaxas, A. (2010). Understanding population dynamics of a numerically dominant species at hydrothermal vents: a matrix modeling approach. Mar. Ecol. Progr. Series 403, 113-128. doi: 10.3354/meps08442

Kelly, N., Metaxas, A., and Butterfield, D. (2007). Spatial and temporal patterns of colonization by deep-sea hydrothermal vent invertebrates on the Juan de Fuca Ridge, NE Pacific. Aquat. Biol. 1, 1-16. doi: 10.3354/ab00001

Keymer, J. E., Marquet, P. A., and Johnson, A. R. (1998). Pattern formation in a patch occupancy metapopulation model: a cellular automata approach. $J$. Theor. Biol. 194, 79-90. doi: 10.1006/jtbi.1998.0745

Kiel, S. (2016). A biogeographic network reveals evolutionary links between deepsea hydrothermal vent and methane seep faunas. Proc. R. Soc. B Biol. Sci. 283:20162337 . doi: 10.1098/rspb.2016.2337

Kingman, J. F. C. (1982). The coalescent. Stochas. Process. Their Appl. 13, 235-248. doi: 10.1016/0304-4149(82)90011-4

Kinlan, B. P., and Gaines, S. D. (2003). Propagule dispersal in marine and terrestrial environments: a community perspective. Ecology 84, 2007-2020. doi: 10.1890/01-0622

Klose, J., Polz, M. F., Wagner, M., Schimak, M. P., Gollner, S., and Bright, M. (2015). Endosymbionts escape dead hydrothermal vent tubeworms to enrich the free-living population. Proc. Natl. Acad. Sci. U.S.A. 112, 11300-11305. doi: $10.1073 /$ pnas. 1501160112

Kneitel, J. M., and Miller, T. E. (2003). Dispersal rates affect species composition in metacommunities of Sarracenia purpurea inquilines. Am. Nat. 162, 165-171. doi: $10.1086 / 376585$

Kojima, S., and Watanabe, H. (2015). "Vent fauna in the Mariana Trough," in Subseafloor Biosphere Linked to Hydrothermal Systems: TAIGA Concept, eds J. Ishibashi, K. Okino, and M. Sunamura (Tokyo: Springer), 313-323.

Kumagai, H., Watanabe, H., Yahagi, T., Kojima, S., Nakai, S., Toyoda, S., et al. (2015). "Evaluating hydrothermal system evolution using geochronological dating and biological diversity analyses," in Subseafloor Biosphere Linked to Hydrothermal Systems; TAIGA Concept, eds J. Ishibashi, K. Okino, and M. Sunamura (Tokyo: Springer), 49-59.

Lalou, C., Brichet, E., and Hekinian, R. (1985). Age dating of sulfide deposits from axial and off-axial structures on the East Pacific Rise near $12^{\circ} 50^{\prime}$ N. Earth Planet. Sci. Lett. 75, 59-71. doi: 10.1016/0012-821X(85)90050-0

Lavelle, J. W., and Mohn, C. (2010). Motion, commotion, and biophysical connections at deep ocean seamounts. Oceanography 23, 90-103. doi: 10.5670/oceanog.2010.64

Lavelle, J. W., Thurnherr, A. M., Ledwell, J. R., McGillicuddy, D. J., and Mullineaux, L. S. (2010). Deep ocean circulation and transport where the East Pacific Rise at 9-10 $\mathrm{N}$ meets the Lamont seamount chain. J. Geophys. Res. Oceans 115:C12073. doi: 10.1029/2010JC006426

Le Bris, N., Govenar, B., Le Gall, C., and Fisher, C. R. (2006). Variability of physicochemical conditions in $9^{\circ} 50^{\prime} \mathrm{N}$ EPR diffuse flow vent habitats. Mar. Chem. 98 , 167-182. doi: 10.1016/j.marchem.2005.08.008

Legendre, P., Borcard, D., and Peres-Neto, P. R. (2005). Analyzing beta diversity: partitioning the spatial variation of community composition data. Ecol. Monogr. 75, 435-450. doi: 10.1890/05-0549

Leibold, M. A., Holyoak, M., Mouquet, N., Amarasekare, P., Chase, J. M., Hoopes, M. F., et al. (2004). The metacommunity concept: a framework for multi-scale community ecology. Ecol. Lett. 7, 601-613. doi: 10.1111/j.1461-0248.2004.00608.x 
Levin, L. A. (2005). Ecology of cold seep sediments: interactions of fauna with flow, chemistry and microbes. Oceanogr. Mar. Biol. Annu. Rev. 43, 1-46. doi: 10.1201/9781420037449.ch1

Levin, L. A., Baco, A. R., Bowden, D. A., Colaco, A., Cordes, E. E., Cunha, M. R., et al. (2016a). Hydrothermal vents and methane seeps: rethinking the sphere of influence. Front. Mar. Sci. 3:72. doi: 10.3389/fmars.2016.00072

Levin, L. A., Mendoza, G. F., and Grupe, B. M. (2017). Methane seepage effects on biodiversity and biological traits of macrofauna inhabiting authigenic carbonates. Deep Sea Res. II Top. Stud. Oceanogr. 137, 26-41. doi: $10.1016 /$ j.dsr2.2016.05.021

Levin, L. A., Mendoza, G. F., Grupe, B. M., Gonzalez, J. P., Jellison, B., Rouse, G., et al. (2015). Biodiversity on the rocks: macrofauna inhabiting authigenic carbonate at Costa Rica methane deeps. PLoS ONE 10:e0131080. doi: 10.1371/journal.pone.0131080

Levin, L. A., Mengerink, K., Gjerde, K. M., Rowden, A. A., Van Dover, C. L., Clark, M. R., et al. (2016b). Defining "serious harm" in the context of deep-sea mining. Mari. Policy 74, 245-259. doi: 10.1016/j.marpol.2016.09.032

Levin, L. A., Orphan, V. J., Rouse, G. W., Rathburn, A. E., Ussler, W., Cook, G. S., et al. (2012). A hydrothermal seep on the Costa Rica margin: middle ground in a continuum of reducing ecosystems. Proc. R. Soc. B Biol. Sci. 279, 2580-2588. doi: $10.1098 /$ rspb. 2012.0205

Levin, L. A., Ziebis, W., Mendoza, G. F., Bertics, V. J., Washington, T., Gonzalez, J., et al. (2013). Ecological release and niche partitioning under stress: lessons from dorvilleid polychaetes in sulfidic sediments at methane seeps. Deep Sea Res. II Top. Stud. Oceanogr. 92, 214-233. doi: 10.1016/j.dsr2.2013.02.006

Levin, L. A., Ziebis, W., Mendoza, G. F., Growney-Cannon, V., and Walther, S. (2006). Recruitment response of methane-seep macrofauna to sulfide-rich sediments: an in situ experiment. J. Exp. Mar. Biol. Ecol. 330, 132-150. doi: 10.1016/j.jembe.2005.12.022

Levin, S. A., Muller-Landau, H. C., Nathan, R., and Chave, J. (2003). The ecology and evolution of seed dispersal: a theoretical perspective. Ann. Rev. Ecol. Syst. 34, 575-604. doi: 10.1146/annurev.ecolsys.34.011802.132428

Levins, R. (1969). Some demographic and genetic consequences of environmental heterogeneity for biological control. Bull. Entomol. Soc. Am. 15, 237-240. doi: 10.1093/besa/15.3.237

Levins, R. (1970). Patch occupancy models. Lect. Math. Life Sci. 2, 77-107.

Logue, J. B., Mouquet, N., Peter, H., Hillebrand, H., and Metacommunity Working, G. (2011). Empirical approaches to metacommunities: a review and comparison with theory. Trends Ecol. Evol. 26, 482-491. doi: 10.1016/j.tree.2011.04.009

Lotze, H. K., Coll, M., Magera, A. M., Ward-Paige, C., and Airoldi, L. (2011). Recovery of marine animal populations and ecosystems. Trends Ecol. Evol. 26, 595-605. doi: 10.1016/j.tree.2011.07.008

Lowe, W. H., and Allendorf, F. W. (2010). What can genetics tell us about population connectivity? Mol. Ecol. 19, 5320-5320. doi: 10.1111/j.1365-294X.2010.04878.x

Lupton, J. E. (1998). Hydrothermal helium plumes in the Pacific Ocean. J. Geophys. Res. 103, 15853-15868. doi: 10.1029/98JC00146

Luther, G. W., Rozan, T. F., Taillefert, M., Nuzzio, D. B., Di Meo, C., Shank, T. M., et al. (2001). Chemical speciation drives hydrothermal vent ecology. Nature 410, 813-816. doi: 10.1038/35071069

MacDonald, I. R., Garcia-Pineda, O., Beet, A., Daneshgar Asl, S., Feng, L., Graettinger, G., et al. (2015). Natural and unnatural oil slicks in the Gulf of Mexico. J. Geophys. Res. Oceans 120, 8364-8380. doi: 10.1002/2015JC011062

MacNeil, M. A., Graham, N. A., Polunin, N. V., Kulbicki, M., Galzin, R., HarmelinVivien, M., et al. (2009). Hierarchical drivers of reef-fish metacommunity structure. Ecology 90, 252-264. doi: 10.1890/07-0487.1

Magurran, A. E. (2004). Measuring Biological Diversity. Malden, MA: WileyBlackwell.

Mangel, M., and Tier, C. (1994). Four facts every conservation biologist should know about persistence. Ecology 75, 607-614. doi: 10.2307/1941719

Marcus, J., Tunnicliffe, V., and Butterfield, D. A. (2009). Post-eruption succession of macrofaunal communities at diffuse flow hydrothermal vents on Axial Volcano, Juan de Fuca Ridge, Northeast Pacific. Deep Sea Res. II Top. Stud. Oceanogr. 56, 1586-1598. doi: 10.1016/j.dsr2.2009.05.004

Marsh, A. G., Mullineaux, L. S., Young, C. M., and Manahan, D. T. (2001). Larval dispersal potential of the tubeworm Riftia pachyptila at deep-sea hydrothermal vents. Nature 411, 77-80. doi: 10.1038/35075063
Marsh, L., Copley, J. T., Huvenne, V. A., Linse, K., Reid, W. D., Rogers, A. D., et al. (2012). Microdistribution of faunal assemblages at deep-sea hydrothermal vents in the Southern Ocean. PLoS ONE 7:e48348. doi: 10.1371/journal.pone.0048348

Matabos, M., Le Bris, N., Pendlebury, S., and Thiébaut, E. (2008a). Role of physicochemical environment on gastropod assemblages at hydrothermal vents on the East Pacific Rise (13 ${ }^{\circ}$ N/EPR). J. Mar. Biol. Assoc. U.K. 88, 995-1008. doi: $10.1017 /$ S002531540800163X

Matabos, M., Thiebaut, E., Le Guen, D., Sadosky, F., Jollivet, D., and Bonhomme, F. (2008b). Geographic clines and stepping-stone patterns detected along the East Pacific Rise in the vetigastropod Lepetodrilus elevatus reflect species crypticism. Mar. Biol. 153, 545-563. doi: 10.1007/s00227-007-0829-3

McGillicuddy, D. J., Lavelle, J. W., Thurnherr, A. M., Kosnyrev, V. K., and Mullineaux, L. S. (2010). Larval dispersion along an axially symmetric midocean ridge. Deep Sea Res. I 57, 880-892. doi: 10.1016/j.dsr.2010.04.003

Meirmans, P. G. (2014). Nonconvergence in Bayesian estimation of migration rates. Mol. Ecol. Resour. 14, 726-733. doi: 10.1111/1755-0998.12216

Mengerink, K. J., Van Dover, C. L., Ardron, J., Baker, M., Escobar-Briones, E., Gjerde, K., et al. (2014). A call for deep-ocean stewardship. Science 344, 696-698. doi: 10.1126/science. 1251458

Metaxas, A. (2004). Spatial and temporal patterns in larval supply at hydrothermal vents in the northeast Pacific Ocean. Limnol. Oceanogr. 49, 1949-1956. doi: $10.4319 /$ lo.2004.49.6.1949

Metaxas, A. (2011). Spatial patterns of larval abundance at hydrothermal vents on seamounts: evidence for recruitment limitation. Mar. Ecol. Prog. Ser. 437, 103-117. doi: $10.3354 /$ meps 09283

Micheli, F., Peterson, C. H., Mullineaux, L. S., Fisher, C., Mills, S. W., Sancho, G., et al. (2002). Predation structures communities at deep-sea hydrothermal vents. Ecol. Monogr. 72, 365-338. doi: 10.1890/0012-9615(2002)072[0365:PSCADS]2. $0 . \mathrm{CO} ; 2$

Mills, S. W., Mullineaux, L. S., Beaulieu, S. E., and Adams, D. K. (2013). Persistent effects of disturbance on larval patterns in the plankton after an eruption on the East Pacific Rise. Mar. Ecol. Prog. Ser. 491, 67-76. doi: 10.3354/meps10463

Mills, S. W., Mullineaux, L. S., and Tyler, P. A. (2007). Habitat associations in gastropod species at East Pacific Rise hydrothermal vents $\left(9^{\circ} 50^{\prime} \mathrm{N}\right)$. Biol. Bull. 212, 185-194. doi: 10.2307/25066601

Mitarai, S., Watanabe, H., Nakajima, Y., Shchepetkin, A. F., and McWilliams, J. C. (2016). Quantifying dispersal from hydrothermal vent fields in the western Pacific Ocean. Proc. Natl. Acad. Sci. U.S.A. 113, 2976-2981. doi: 10.1073/pnas.1518395113

Miyake, H., Tsukahara, J., Hashimoto, J., Eumatsu, K., and Maruyama, T. (2006). Rearing and observation methods of vestimentiferan tubeworm and its early development at atmospheric pressure. Cah. Biol. Mar. 47, 471-475.

Miyazaki, J. I., Beppu, S., Kajio, S., Dobashi, A., Kawato, M., Fujiwara, Y., et al. (2013). Dispersal ability and environmental adaptability of deep-sea mussels Bathymodiolus (Mytilidae: Bathymodiolinae). Open J. Mar. Sci. 3, 31-39. doi: 10.4236/ojms.2013.31003

Moalic, Y., Desbruyères, D., Duarte, C. M., Rozenfeld, A. F., Bachraty, C., and Arnaud-Haond, S. (2012). Biogeography revisited with network theory: retracing the history of hydrothermal vent communities. Syst. Biol. 61, 127-137. doi: $10.1093 /$ sysbio/syr088

Molofsky, J. (1994). Population-dynamics and pattern-formation in theoretical populations. Ecology 75, 30-39. doi: 10.2307/1939379

Mottl, M. J., Seewald, J. S., Wheat, C. G., Tivey, M. K., Michael, P. J., Proskurowski, G., et al. (2011). Chemistry of hot springs along the Eastern Lau Spreading Center. Geochim. Cosmochim. Acta 75, 1013-1038. doi: 10.1016/j.gca.2010.12.008

Mullineaux, L. S. (2014). "Deep-sea hydrothermal vent communities," in Marine Community Ecology and Conservation, eds M. D. Bertness, J. F. Bruno, B. R. Silliman, and J. J. Stachowicz (Sunderland, MA: Sinauer), 383-400.

Mullineaux, L. S., Adams, D. K., Mills, S. W., and Beaulieu, S. E. (2010). Larvae from afar colonize deep-sea hydrothermal vents after a catastrophic eruption. Proc. Natl. Acad. Sci. U.S.A. 107, 7829-7834. doi: 10.1073/pnas.091 3187107

Mullineaux, L. S., Fisher, C. R., Peterson, C. H., and Schaeffer, S. W. (2000). Vestimentiferan tubeworm succession at hydrothermal vents: use of biogenic cues to reduce habitat selection error? Oecologia 123, 275-284. doi: $10.1007 /$ s004420051014 
Mullineaux, L. S., Le Bris, N., Mills, S. W., Henri, P., Bayer, S. R., Secrist, R. G., et al. (2012). Detecting the influence of initial pioneers on succession at deep-sea vents. PLOS ONE 7:e50015. doi: 10.1371/journal.pone.0050015

Mullineaux, L. S., McGillicuddy, D. J., Mills, S. W., Kosnyrev, V. K., Thurnherr, A. M., Ledwell, J. R., et al. (2013). Active positioning of vent larvae at a mid-ocean ridge. Deep Sea Res. II Top. Stud. Oceanogr. 92, 46-57. doi: $10.1016 /$ j.dsr2.2013.03.032

Mullineaux, L. S., Mills, S. W., Sweetman, A. K., Beaudreau, A. H., Metaxas, A., and Hunt, H. L. (2005). Spatial structure and temporal variation in larval abundance at hydrothermal vents on the East Pacific Rise. Mar. Ecol. Prog. Ser. 293, 1-16. doi: 10.3354/meps 293001

Mullineaux, L. S., Peterson, C. H., Micheli, F., and Mills, S. W. (2003). Successional mechanism varies along a gradient in hydrothermal fluid flux at deep-sea vents. Ecol. Monogr. 73, 523-542. doi: 10.1890/02-0674

Musick, J. A. (1999). Criteria to define extinction risk in marine fishes - the American Fisheries Society initiative. Fisheries 24, 6-14.

Neubert, M. G., Mullineaux, L. S., and Hill, M. F. (2006). "A metapopulation approach to interpreting diversity at deep-sea hydrothermal vents," in Marine Metapopulations, eds J. P. Kritzer and P. F. Sale (London: Elsevier), 321-350.

O'Mullan, G. D., Maas, P. A., Lutz, R. A., and Vrijenhoek, R. C. (2001). A hybrid zone between hydrothermal vent mussels (Bivalvia: Mytilidae) from the Mid-Atlantic Ridge. Mol. Ecol. 10, 2819-2831. doi: 10.1046/j.0962-1083.2001.01401.x

Ovaskainen, O., and Hanski, I. (2003). Extinction threshold in metapopulation models. Ann. Zool. Fenn. 40, 81-97.

Perfit, M. R., and Chadwick, W. W. (1998). "Magmatism at mid-ocean ridges: constraints from volcanological and geochemical investigations," in Faulting and Magmatism at Mid-Ocean Ridges, Geophys Monograph 116, eds W. R. Buck, P. Delaney, and J. A. Karson (Washington, DC: American Geophysical Union), 59-116.

Piry, S., Alapetite, A., Cornuet, J. M., Paetkau, D., Baudouin, L., and Estoup, A. (2004). GENECLASS2: a software for genetic assignment and firstgeneration migrant detection. J. Heredity 95, 536-539. doi: 10.1093/jhered/ esh074

Plouviez, S., Faure, B., Le Guen, D., Lallier, F. H., Bierne, N., and Jollivet, D. (2013). A new barrier to dispersal trapped old genetic clines that escaped the Easter Microplate tension zone of the Pacific vent mussels. PLoS ONE 8:e81555. doi: 10.1371/journal.pone.0081555

Plouviez, S., Jacobson, A., Wu, M. Y., and Van Dover, C. L. (2015). Characterization of vent fauna at the Mid-Cayman Spreading Center. Deep Sea Res. I Oceanogr. Res. Pap. 97, 124-133. doi: 10.1016/j.dsr.2014.11.011

Plouviez, S., Le Guen, D., Lecompte, O., Lallier, F. H., and Jollivet, D. (2010). Determining gene flow and the influence of selection across the equatorial barrier of the East Pacific Rise in the tube-dwelling polychaete Alvinella pompejana. BMC Evol. Biol. 10:220. doi: 10.1186/1471-2148-10-220

Plouviez, S., Shank, T. M., Faure, B., Daguin-Thiebaut, C., Viard, F., Lallier, F. H., et al. (2009). Comparative phylogeography among hydrothermal vent species along the East Pacific Rise reveals vicariant processes and population expansion in the South. Mol. Ecol. 18, 3903-3917. doi: 10.1111/j.1365-294X.2009.0 4325. $x$

Podowski, E. L., Ma, S., Luther Iii, G. W., Wardrop, D., and Fisher, C. R. (2010). Biotic and abiotic factors affecting distributions of megafauna in diffuse flow on andesite and basalt along the Eastern Lau Spreading Center, Tonga. Mar. Ecol. Prog. Ser. 418, 25-45. doi: 10.3354/meps08797

Pond, D. W., Gebruk, A., Southward, E. C., Southward, A. J., Fallick, A. E., Bell, M. V., et al. (2000). Unusual fatty acid composition of storage lipids in the bresilioid shrimp Rimicaris exoculata couples the photic zone with MAR hydrothermal vent sites. Mar. Ecol. Prog. Ser. 198, 171-179. doi: 10.3354/meps198171

Pradillon, F., Le Bris, N., Shillito, B., Young, C. M., and Gaill, F. (2005). Influence of environmental conditions on early development of the hydrothermal vent polychaete Alvinella pompejana. J. Exp. Biol. 208, 1551-1561. doi: 10.1242/jeb.01567

QGIS DevelopmentTeam (2017). QGIS Geographic Information System. Open Source Geospatial Foundation Project. Available online at: http://www.qgis.org

Reid, W. D., Sweeting, C. J., Wigham, B. D., Zwirglmaier, K., Hawkes, J. A., McGill, R. A., et al. (2013). Spatial differences in East Scotia Ridge hydrothermal vent food webs: influences of chemistry, microbiology and predation on trophodynamics. PLoS ONE 8:e65553. doi: 10.1371/journal.pone.00 65553

Reitzel, A. M., Herrera, S., Layden, M. J., Martindale, M. Q., and Shank, T. M. (2013). Going where traditional markers have not gone before: utility of and promise for RAD sequencing in marine invertebrate phylogeography and population genomics. Mol. Ecol. 22, 2953-2970. doi: 10.1111/mec. 12228

Roterman, C. N., Copley, J. T., Linse, K. T., Tyler, P. A., and Rogers, A. D. (2016). Connectivity in the cold: the comparative population genetics of ventendemic fauna in the Scotia Sea, Southern Ocean. Mol. Ecol. 25, 1073-1088. doi: $10.1111 /$ mec. 13541

Rubin, K. H., Soule, S. A., Chadwick, W. W., Fornari, D. J., Clague, D. A., Embley, R. W., et al. (2012). Volcanic eruptions in the deep sea. Oceanography 25, 142-157. doi: 10.5670/oceanog.2012.12

Sahling, H., Masson, D. G., Ranero, C. R., Hühnerbach, V., Weinrebe, W., Klaucke, I., et al. (2008). Fluid seepage at the continental margin offshore Costa Rica and southern Nicaragua. Geochem. Geophys. Geosyst. 9:Q05S05. doi: 10.1029/2008GC001978

Sahling, H., Rickert, D., Lee, R. W., Linke, P., and Suess, E. (2002). Macrofaunal community structure and sulfide flux at gas hydrate deposits from the Cascadia convergent margin, NE Pacific. Mar. Ecol. Progr. Series 231, 121-138. doi: 10.3354/meps231121

Sale, P. F., Hanski, I., and Kritzer, J. P. (eds.). (2006). The Merging of Metapopulation Theory and Marine Ecology: Establishing the Historical Context. San Diego, CA: Academic Press.

Sancho, G., Fisher, C. R., Mills, S., Micheli, F., Johnson, G. A., Lenihan, H. S., et al. (2005). Selective predation by the zoarcid fish Thermarces cerberus at hydrothermal vents. Deep Sea Res. 52, 837-844. doi: 10.1016/j.dsr.2004.12.002

Sarrazin, J., and Juniper, S. K. (1999). Biological characteristics of a hydrothermal edifice mosaic community. Mar. Ecol. Progr. Ser. 185, 1-19. doi: $10.3354 /$ meps 185001

Sarrazin, J., Juniper, S. K., Massoth, G., and Legendre, P. (1999). Physical and chemical factors influencing species distributions on hydrothermal sulfide edifices of the Juan de Fuca Ridge, northeast Pacific. Mar. Ecol. Progr. Series 190, 89-112. doi: 10.3354/meps190089

Sarrazin, J., Legendre, P., de Busserolles, F., Fabri, M. C., Guilini, K., Ivanenko, V. N., et al. (2015). Biodiversity patterns, environmental drivers and indicator species on a high-temperature hydrothermal edifice, Mid-Atlantic Ridge. Deep Sea Res. II Top. Stud. Oceanogr. 121, 177-192. doi: 10.1016/j.dsr2.2015.04.013

Sarrazin, J., Robigou, V., Juniper, S. K., and Delaney, J. R. (1997). Biological and geological dynamics over four years on a high-temperature sulfide structure at the Juan de Fuca Ridge hydrothermal observatory. Mar. Ecol. Progr. Series 153, 5-24. doi: 10.3354/meps 153005

Saunders, P. M., and Francis, T. J. (1985). The search for hydrothermal sources on the Mid-Atlantic Ridge. Prog. Oceanogr. 14, 527-536. doi: 10.1016/0079-6611(85)90026-6

Schnur, S. R., Chadwick, W. W., Embley, R. W., Ferrini, V. L., de Ronde, C. E. J., Cashman, K. V., et al. (2017). A decade of volcanic construction and destruction at the summit of NW Rota-1 seamount: 2004-2014. J. Geophys. Res. Solid Earth 122, 1558-1584. doi: 10.1002/2016JB013742

Schrenk, M. O., Brazelton, W. J., and Lang, S. Q. (2013). Serpentinization, carbon, and deep life. Carbon Earth 75, 575-606. doi: 10.2138/rmg.2013.75.18

Sen, A., Podowski, E. L., Becker, E. L., Shearer, E. A., Gartman, A., Yucel, M., et al. (2014). Community succession in hydrothermal vent habitats of the Eastern Lau Spreading Center and Valu Fa Ridge, Tonga. Limnol. Oceanogr. 59, 1510-1528. doi: 10.4319/lo.2014.59.5.1510

Shank, T. M., Fornari, D. J., von Damm, K. L., Lilley, M. D., Haymon, R. M., and Lutz, R. A. (1998). Temporal and spatial patterns of biological community development at nascent deep-sea hydrothermal vents $\left(9^{\circ} 50^{\prime} \mathrm{N}\right.$, East Pacific Rise). Deep Sea Res. II 45, 465-515. doi: 10.1016/S0967-0645(97)00089-1

Shen, Y., Kou, Q., Chen, W., He, S., Yang, M., Li, X., et al. (2016). Comparative population structure of two dominant species, Shinkaia crosnieri (Munidopsidae: Shinkaia) and Bathymodiolus platifrons (Mytilidae: Bathymodiolus), inhabiting both deep-sea vent and cold seep inferred from mitochondrial multi-genes. Ecol. Evol. 6, 3571-3582. doi: 10.1002/ece3.2132

Short, J., and Metaxas, A. (2011). Gregarious settlement of tubeworms at deep-sea hydrothermal vents on the Tonga - Kermadec arc, South Pacific. J. Mar. Biol. Assoc. U.Ki. 91, 15-22. doi: 10.1017/S0025315410000676 
Siegel, D. A., Mitarai, S., Costello, C. J., Gaines, S. D., Kendall, B. E., Warner, R. R., et al. (2008). The stochastic nature of larval connectivity among nearshore marine populations. Proc. Natl. Acad. Sci. U.S.A. 105, 8974-8979. doi: 10.1073/pnas.0802544105

Sievert, S. M., and Vetriani, C. (2012). Chemoautotrophy at deep-sea vents past, present, and future. Oceanography 25, 218-233. doi: 10.5670/oceanog.2012.21

Skarke, A., Ruppel, C., Kodis, M., Brothers, D., and Lobecker, E. (2014). Widespread methane leakage from the sea floor on the northern US Atlantic margin. Nat. Geosci. 7, 657-661. doi: 10.1038/ngeo2232

Speer, K. G., Trequier, A. M., Hogg, N. G., Maltrud, M., and Thierry, V. (2003). On the origin of deep zonal flows in the Brazil Basin. J. Phys. Oceanogr. 33, 580-599. doi: 10.1175/1520-0485(2003)033\&lt;0580:TOODZF\&gt;2.0.CO;2

Steiner, R. (2009). "independent review of the environmental impact statement for the proposed nautilus minerals solwara 1 seabed mining project, Papua New Guinea," in Report for the Bismarck-Solomon Seas Indigenous Peoples Council (Madang).

Stern, R. J., Fouch, J., and Klemperer, S. L. (2013). "An overview of the IzuBonin-Mariana subduction factory," in Inside the Subduction Factory, ed J. Eiler (American Geophysical Union), 175-222.

Stevens, C. J., Juniper, S. K., Limen, H., Pond, D. W., Metaxas, A., and Gelinas, Y. (2015). Obligate hydrothermal vent fauna at East Diamante submarine volcano (Mariana Arc) exploit photosynthetic and chemosynthetic carbon sources. Mar. Ecol. Prog. Ser. 525, 25-39. doi: 10.3354/meps11229

Stiller, J., Rousset, V., Pleijel, F., Chevaldonne, P., Vrijenhoek, R. C., and Rouse, G. W. (2013). Phylogeny, biogeography and systematics of hydrothermal vent and methane seep Amphisamytha (Ampharetidae, Annelida), with descriptions of three new species. Syst. Biodivers. 11, 35-65. doi: 10.1080/14772000.2013.772925

Tao, C. H., Li, H. M., Jin, X. B., Zhou, J. P., Wu, T., He, Y. H., et al. (2014). Seafloor hydrothermal activity and polymetallic sulfide exploration on the southwest Indian ridge. Chinese Sci. Bull. 59, 2266-2276. doi: 10.1007/s11434-014-0182-0

Teixeira, S., Olu, K., Decker, C., Cunha, R. L., Fuchs, S., Hourdez, S., et al. (2013). High connectivity across the fragmented chemosynthetic ecosystems of the deep Atlantic Equatorial Belt: efficient dispersal mechanisms or questionable endemism? Mol. Ecol. 22, 4663-4680. doi: 10.1111/mec.12419

Teixeira, S., Serrão, E. A., and Arnaud-Haond, S. (2012). Panmixia in a fragmented and unstable environment: the hydrothermal shrimp Rimicaris exoculata disperses extensively along the mid-atlantic ridge. PLOS ONE 7:e38521. doi: 10.1371/journal.pone.0038521

Thaler, A. D., Plouviez, S., Saleu, W., Alei, F., Jacobson, A., Boyle, E. A., et al. (2014). Comparative population structure of two deep-sea hydrothermal-vent-associated decapods (Chorocaris sp. 2 and Munidopsis lauensis) from southwestern pacific back-arc basins. PLoS ONE 9:e101345. doi: 10.1371/journal.pone.0101345

Thaler, A. D., Zelnio, K., Saleu, W., Schultz, T. F., Carlsson, J., Cunningham, C., et al. (2011). The spatial scale of genetic subdivision in populations of Ifremeria nautilei, a hydrothermal-vent gastropod from the southwest Pacific. BMC Evol. Biol. 11:372. doi: 10.1186/1471-2148-11-372

Thomson, R. E., Mihály, S. F., Rabinovich, A. B., McDuff, R. E., Veirs, S. R., and Stahr, F. R. (2003). Constrained circulation at Endeavour ridge facilitates colonization by vent larvae. Nature 424, 545-549. doi: 10.1038/nature 01824

Thomson, R. E., Subbotina, M. M., and Anisimov, M. V. (2009). Numerical simulation of mean currents and water property anomalies at Endeavour Ridge: hydrothermal versus topographic forcing. J. Geophys. Res. 114:C09020. doi: 10.1029/2008JC005249

Thrush, S. F., Halliday, J., Hewitt, J. E., and Lohrer, A. M. (2008). The effects of habitat loss, fragmentation and community homogenization on resilience in estuaries. Ecol. Appl. 18, 12-21. doi: 10.1890/07-0436.1

Thurnherr, A. M., and St. Laurent, L. C. (2011). Turbulence and diapycnal mixing over the East Pacific Rise crest near $10^{\circ}$ N. Geophys. Res. Lett. 38:L15613, L15614. doi: 10.1029/2011gl048207

Thurnherr, A. M., Ledwell, J. R., Lavelle, J. W., and Mullineaux, L. S. (2011). Hydrography and circulation near the crest of the East Pacific Rise between 90 degrees and 10 degrees N. Deep Sea Res. I Oceanogr. Res. Pap. 58, 365-376. doi: 10.1016/j.dsr.2011.01.009

Thurnherr, A. M., Reverdin, G., Bouruet-Aubertot, P., St Laurent, L. C., Vangriesheim, A., and Ballu, V. (2008). Hydrography and flow in the
Lucky Strike segment of the Mid-Atlantic Ridge. J. Mar. Res. 66, 347-372. doi: 10.1357/002224008786176034

Thurnherr, A. M., Richards, K. J., German, C. R., Lane-Serff, G. F., and Speer, K. G. (2002). Flow and mixing in the rift valley of the Mid-Atlantic Ridge. J. Phys. Oceanogr. 32, 1763-1778. doi: 10.1175/15200485(2002)032\&lt;1763:FAMITR\&gt;2.0.CO;2

Tolstoy, M., Cowen, J. P., Baker, E. T., Fornari, D. J., Rubin, K. H., Shank, T. M., et al. (2006). A sea-floor spreading event captured by seismometers. Science 314, 1920-1922. doi: 10.1126/science. 1133950

Trakhtenbrot, A., Nathan, R., Perry, G., and Richardson, D. M. (2005). The importance of long-distance dispersal in biodiversity conservation. Divers. Distrib. 11, 173-181. doi: 10.1111/j.1366-9516.2005.00156.x

Trask, J. L., and Van Dover, C. L. (1999). Site-specific and ontogenetic variations in nutrition of mussels (Bathymodiolus sp.) from the Lucky Strike hydrothermal vent field, Mid-Atlantic Ridge. Limnol. Oceanogr. 44, 334-343. doi: 10.4319/lo.1999.44.2.0334

Tsurumi, M. (2003). Diversity at hydrothermal vents. Glob. Ecol. Biogeogr. 12, 181-190. doi: 10.1046/j.1466-822X.2003.00016.x

Tsurumi, M., and Tunnicliffe, V. (2001). Characteristics of a hydrothermal vent assemblage on a volcanically active segment of Juan de Fuca Ridge, northeast Pacific. Can. J. Fish. Aquat. Sci. 58, 530-542. doi: 10.1139/f01-005

Tsurumi, M., and Tunnicliffe, V. (2003). Tubeworm-associated communities at hydrothermal vents on the Juan de Fuca Ridge, northeast Pacific. Deep Sea Res. 50, 611-629. doi: 10.1016/S0967-0637(03)00039-6

Tunnicliffe, V., Davies, K. T. A., Butterfield, D. A., Embley, R. W., Rose, J. M., and Chadwick, W. W. (2009). Survival of mussels in extremely acidic waters on a submarine volcano. Nat. Geosci. 2, 344-348. doi: 10.1038/ngeo500

Tunnicliffe, V., Embley, R. W., Holden, J. F., Butterfield, D. A., Massoth, G. J., and Juniper, S. K. (1997). Biological colonization of new hydrothermal vents following an eruption on Juan de Fuca Ridge. Deep Sea Res. I 44, 1627-1644. doi: 10.1016/S0967-0637(97)00041-1

Tunnicliffe, V., and Fowler, C. M. R. (1996). Influence of sea-floor spreading on the global hydrothermal vent fauna. Nature 379, 531-533. doi: 10.1038/379531a0

Tunnicliffe, V., Juniper, S. K., and Sibuet, M. (2003). "Reducing environments of the deep-sea floor," in Ecosystems of the World: The Deep Sea, ed P. A. Tyler (Amsterdam: Elsevier), 81-110.

Turnipseed, M., Knick, K. E., Lipcius, R. N., Dreyer, J., and Van Dover, C. L. (2003). Diversity in mussel beds at deep-sea hydrothermal vents and cold seeps. Ecol. Lett. 6, 518-523. doi: 10.1046/j.1461-0248.2003.00465.x

Urban, M. C. (2004). Disturbance heterogeneity determines freshwater metacommunity structure. Ecology 85, 2971-2978. doi: 10.1890/03-0631

Van Dover, C. L. (2000). The Ecology of Deep-Sea Hydrothermal Vents. Princeton, NJ: Princeton University Press.

Van Dover, C. L. (2002). Community structure of mussel beds at deep-sea hydrothermal vents. Mar. Ecol-Prog. Ser. 230, 137-158. doi: 10.3354/meps 230137

Van Dover, C. L. (2011). Mining seafloor massive sulphides and biodiversity: what is at risk? ICES J. Mar. Sci. 68, 341-348. doi: 10.1093/icesjms/fsq086

Van Dover, C. L. (2014). Impacts of anthropogenic disturbances at deep-sea hydrothermal vent ecosystems: a review. Mar. Environ. Res. 102, 59-72. doi: 10.1016/j.marenvres.2014.03.008

Van Dover, C. L., Ardron, J. A., Escobar, E., Gianni, M., Gjerde, K. M., Jaeckel, A., et al. (2017). Biodiversity loss from deep-sea mining. Nat. Geosci. 10, 464-465. doi: $10.1038 /$ ngeo 2983

Van Dover, C. L., German, C. R., Speer, K. G., Parson, L. M., and Vrijenhoek, R. C. (2002). Evolution and biogeography of deep-sea vent and seep invertebrates. Science 295, 1253-1257. doi: 10.1126/science.1067361

Van Dover, C. L., and Hessler, R. R. (1990). "Spatial variation in faunal composition of hydrothermal vent communities on the East Pacific Rise and Galapagos spreading center," in Gorda Ridge, ed G. R. Murray (New York, NY: Springer), $253-264$.

Veirs, S. R., McDuff, R. E., and Stahr, F. R. (2006). Magnitude and variance of near-bottom horizontal heat flux at the Main Endeavour hydrothermal vent field. Geochem. Geophys. Geosyst. 7:Q02004. doi: 10.1029/2005GC0 00952

Vrijenhoek, R. C. (2010). Genetic diversity and connectivity of deepsea hydrothermal vent metapopulations. Mol. Ecol. 19, 4391-4411. doi: 10.1111/j.1365-294X.2010.04789.x 
Wang, J. (2016). A comparison of single-sample estimators of effective population sizes from genetic marker data. Mol. Ecol. 25, 4692-4711. doi: $10.1111 / \mathrm{mec} .13725$

Wang, S., Haegeman, B., and Loreau, M. (2015). Dispersal and metapopulation stability. PeerJ 3:e1295. doi: 10.7717/peerj.1295

Waples, R. S., Luikart, G., Faulkner, J. R., and Tallmon, D. A. (2013). Simple lifehistory traits explain key effective population size ratios across diverse taxa. Proc. R. Soc. B Biol. Sci. 280:20131339. doi: 10.1098/rspb.2013.1339

Watanabe, H., Kado, R., Tsuchida, S., Miyake, H., Kyo, M., and Kojima, S. (2004). Larval development and intermoult period of the hydrothermal vent barnacle Neoverruca sp. J. Mar. Biol. Assoc. U.K. 84, 743-745. doi: 10.1017/S0025315404009841h

Watanabe, H., Tsuchida, S., Fujikura, K., Yamamoto, H., Inagaki, F., Kyo, M., et al. (2005). Population history associated with hydrothermal vent activity inferred from genetic structure of neoverrucid barnacles around Japan. Mar. Ecol. Prog. Ser. 288, 233-240. doi: 10.3354/meps 288233

Watanabe, M., Okino, K., and Kodera, T. (2010). Rifting to spreading in the southern Lau Basin: variations within the transition zone. Tectonophysics 494, 226-234. doi: 10.1016/j.tecto.2010.09.001

Watson, J. R., Siegel, D. A., Kendall, B. E., Mitarai, S., Rassweiller, A., and Gaines, S. D. (2011). Identifying critical regions in small-world marine metapopulations. Proc. Natl. Acad. Sci. U.S.A. 108, E907-E913. doi: 10.1073/pnas.1111461108

Whittaker, R. H. (1972). Evolution and measurement of species diversity. Taxon 21, 213-251. doi: 10.2307/1218190

Wilson, C., Speer, K., Charlou, J. L., Bougault, H., and Klinkhammer, G. (1995). Hydrography above the Mid-Atlantic Ridge $\left(33^{\circ}-40^{\circ} \mathrm{N}\right)$ and within the Lucky Strike segment. J. Geophys. Res. Oceans 100, 20555-20564. doi: 10.1029/95JC02281

Wilson, D. S. (1992). Complex interactions in metacommunities, with implications for biodiversity and higher levels of selection. Ecology 73, 1984-2000. doi: $10.2307 / 1941449$

Wilson, G. A., and Rannala, B. (2003). Bayesian inference of recent migration rates using multilocus genotypes. Genetics 163, 1177-1191.

Wright, S. (1951). The genetical structure of populations. Ann. Eugen. 15, 322-354.

Xu, T., Sun, J., Lv, J., Watanabe, H. K., Li, T. Q., Zou, W. W., et al. (2017). Genome-wide discovery of single nucleotide polymorphisms (SNPs) and single nucleotide variants (SNVs) in deep-sea mussels: potential use in population genomics and cross-species application. Deep Sea Res. II Top. Stud. Oceanogr. 137, 318-326. doi: 10.1016/j.dsr2.2016.03.011

Yahagi, T., Watanabe, H., Ishibashi, J., and Kojima, S. (2015). Genetic population structure of four hydrothermal vent shrimp species (Alvinocarididae) in the Okinawa Trough, Northwest Pacific. Mar. Ecol. Prog. Ser. 529, 159-169. doi: 10.3354/meps11267

Yahagi, T., Kayama Watanabe, H., Kojima, S., and Kano, Y. (2017). Do larvae from deep-sea hydrothermal vents disperse in surface waters? Ecology 98, 1524-1534. doi: $10.1002 /$ ecy.1800

Yang, C. H., Tsuchida, S., Fujikura, K., Fujiwara, Y., Kawato, M., and Chan, T. Y. (2016). Connectivity of the squat lobsters Shinkaia crosnieri (Crustacea: Decapoda: Galatheidae) between cold seep and hydrothermal vent habitats. Bull. Mar. Sci. 92, 17-31. doi: 10.5343/bms.2015.1031

Young, C. R., Fujio, S., and Vrijenhoek, R. C. (2008). Directional dispersal between mid-ocean ridges: deep-ocean circulation and gene flow in Ridgeia piscesae. Mol. Ecol. 17, 1718-1731. doi: 10.1111/j.1365-294X.2008.0 3609.x

Zhang, H. B., Johnson, S. B., Flores, V. R., and Vrijenhoek, R. C. (2015). Intergradation between discrete lineages of Tevnia jerichonana, a deep-sea hydrothermal vent tubeworm. Deep Sea Res. II 121, 53-61. doi: $10.1016 /$ j.dsr2.2015.04.028

Conflict of Interest Statement: LL received past support from Nautilus Minerals Inc. for work on hydrothermal sediments.

The other authors declare that the research was conducted in the absence of any commercial or financial relationships that could be construed as a potential conflict of interest.

Copyright (ㄷ) 2018 Mullineaux, Metaxas, Beaulieu, Bright, Gollner, Grupe, Herrera, Kellner, Levin, Mitarai, Neubert, Thurnherr, Tunnicliffe, Watanabe and Won. This is an open-access article distributed under the terms of the Creative Commons Attribution License (CC BY). The use, distribution or reproduction in other forums is permitted, provided the original author(s) and the copyright owner are credited and that the original publication in this journal is cited, in accordance with accepted academic practice. No use, distribution or reproduction is permitted which does not comply with these terms. 